\title{
Flexible, high-voltage, ion-conducting composite membranes with 3D aramid nanofiber frameworks for stable all-solid-state lithium metal batteries
}

\author{
Lehao Liu ${ }^{1}$, Jing Lyu ${ }^{2}$, Jinshan $\mathrm{Mo}^{1}$, Peng Peng ${ }^{1}$, Jingru $\mathrm{Li}^{1}$, Bing Jiang ${ }^{1}$, Lihua Chu ${ }^{1}$ and \\ Meicheng $\mathrm{Li}^{{ }^{*}}$
}

\begin{abstract}
The practical application of solid polymer electrolytes in high-energy $\mathrm{Li}$ metal batteries is hindered by $\mathrm{Li}$ dendrites, electrochemical instability and insufficient ion conductance. To address these issues, flexible composite polymer electrolyte (CPE) membranes with three dimensional (3D) aramid nanofiber (ANF) frameworks are facilely fabricated by filling polyethylene oxide (PEO)-lithium bis(trifluoromethylsulphonyl)imide (LiTFSI) electrolyte into 3D ANF scaffolds. Because of the unique composite structure design and the continuous ion conduction at the 3D ANF framework/PEO-LiTFSI interfaces, the CPE membranes show higher mechanical strength $(10.0 \mathrm{MPa})$, thermostability, electrochemical stability $\left(4.6 \mathrm{~V}\right.$ at $\left.60^{\circ} \mathrm{C}\right)$ and ionic conductivity than the pristine PEO-LiTFSI electrolyte. Thus, the CPEs display greatly improved interfacial stability against $\mathrm{Li}$ dendrites $\left(\geq 1000 \mathrm{~h}\right.$ at $30^{\circ} \mathrm{C}$ under $\left.0.10 \mathrm{~mA} \mathrm{~cm}^{-2}\right)$, compared with the pristine electrolyte (short circuit in $13 \mathrm{~h}$ ). The CPE-based all-solid-state $\mathrm{LiFePO}_{4} / \mathrm{Li}$ cells also exhibit superior cycling performance (e.g., $130 \mathrm{~mA} \mathrm{~h} \mathrm{~g}^{-1}$ with $93 \%$ retention after 100 cycles at $0.4 \mathrm{C}$ ) than the ANF-free cells (e.g., $82 \mathrm{~mA} \mathrm{~h} \mathrm{~g}^{-1}$ with $66 \%$ retention). This work offers a simple and effective way to achieve high-performance composite electrolyte membranes with 3D nanofiller framework for promising solid-state $\mathrm{Li}$ metal battery applications.
\end{abstract}

Keywords: composite electrolyte, aramid nanofiber, threedimensional scaffold, mechanical stability, Li metal battery

\section{INTRODUCTION}

Lithium-ion batteries (LIBs) are widely applied in many areas such as portable devices and electric vehicles $[1,2]$. The further utilization of Li metal anodes with high ca- pacity $\left(3860 \mathrm{~mA} \mathrm{~h} \mathrm{~g}^{-1}\right)$ and low reduction potential $(-3.04 \mathrm{~V} v s$. standard hydrogen electrode) offers a major way to obtain high-energy-density LIBs $[3,4]$. However, the Li dendrite formation/growth results in serious safety risks such as overheating and short circuit [5,6]. Additionally, the commonly used organic liquid electrolytes with high flammability, narrow electrochemical window and more side reactions aggravate the safety issues $[7,8]$.

Fabricating all-solid-state Li metal batteries with solidstate electrolytes (SSEs) instead of the liquid ones is expected to tackle the aforementioned issues for better safety and higher energy density [4,9]. Solid polymer electrolytes (SPEs) based on polymer matrices and Li salts are promising SSEs in all-solid-state batteries, because of their low density, high flexibility, good film-formation ability, easy fabrication, excellent interfacial compatibility with electrodes, and low cost [10]. Compared with other polymers, polyethylene oxide (PEO) has good capacity of dissolving $\mathrm{Li}$ salts and relatively high ion conductivity, and thus is regarded as one of the most important polymer matrices for SPEs [11]. Unfortunately, the SPEs with insufficient mechanical strength suffer from the penetration of $\mathrm{Li}$ dendrites especially under high current densities $[3,5,12] . \mathrm{Li}^{+}$ions can move in the free volume of the polymer matrices by inter/intra-chain hopping, but the high crystallization of the polymer matrices causes the low ionic conductivity $\left(10^{-8}-10^{-6} \mathrm{~S} \mathrm{~cm}^{-1}\right)$ of the SPEs at ambient temperature, due to the slow-down dynamics of the polymer chains $[5,13,14]$. With the increasing ionic conductance at elevating temperatures, the SPEs lose mechanical strength and dimensional stability in the molten state $[5,15]$. Besides, the low oxidation potential of

\footnotetext{
${ }^{1}$ State Key Laboratory of Alternate Electrical Power System with Renewable Energy Sources, School of Renewable Energy, North China Electric Power University, Beijing 102206, China

${ }^{2}$ Suzhou Institute of Nano-tech and Nano-bionics, Chinese Academy of Sciences, Suzhou 215123, China

* Corresponding author (email: mcli@ncepu.edu.cn)
} 
the SPEs impedes their practical applications in highenergy batteries $[4,16,17]$. Thus, it is necessary to comprehensively improve the SPE properties for better Li metal battery performance.

Recently tremendous effort has been focused on preparing composite polymer electrolytes (CPEs) by adding inorganic nanofillers into the polymer matrices to enhance the mechanical properties, electrochemical stability and ionic conductivity [18-25]. Nevertheless, it is difficult to greatly increase the mechanical strength by using the nanofillers for commercial applications due to the failure of forming interconnected reinforcements $[3,26]$. Moreover, the room-temperature ion conductivity cannot be greatly improved, because of the low dispersity of the high-surface-area nanofillers, poor interactions between the nanofiller and the electrolyte matrices, and short ion transport pathways between the nanofiller/polymer-Li salt interfaces [13,25,27-29]. To address these issues, constructing special CPEs by filling the SPEs in porous inorganic films as three-dimensional (3D) scaffolds has been reported to significantly enhance the thermal stability, electrochemical window and ionic conductivity [30-36]; however, there are few reports on the mechanical properties of these CPEs and the cycling performance of the CPE-based all-solid-state batteries, possibly due to the high stiffness/brittleness of the ceramic scaffolds. The preparation of the $3 \mathrm{D}$ inorganic scaffolds by electrospinning [30-32,37,38], hydrogel [35,36], aerogel [26] and template [39] approaches is also not suitable for large-scale electrolyte film production, due to the complicated and time-consuming processes [3]. Using commercial polypropylene (PP) separators instead of the inorganic scaffolds can improve the flexibility and mechanical strength of the CPEs to effectively hinder the Li dendrite growth; however, the 3D PP scaffold-based CPEs exhibit low thermostability and ionic conductivity [40]. In this regard, it is of significance to exploit simple, inexpensive and scalable methods to prepare appropriate 3D scaffolds for desirable CPEs with high flexibility, mechanical strength, thermostability, electrochemical stability and ionic conductivity.

Aramid fibers comprised of poly( $p$-phenylene terephthalamide) (PPTA) have been widely utilized to fabricate high-strength products including body armors, thanks to their outstanding characteristics such as abundant amide groups, high mechanical tensile strength (up to $3.8 \mathrm{GPa}$ ), light weight, large aspect ratio, high thermal decomposition temperature $\left(500^{\circ} \mathrm{C}\right)$, and low electro-conductivity $[41,42]$. Since the discovery of stable aramid nanofiber (ANF) dispersions by Kotov group [43], more and more studies focused on the fabrication of the 1D ANF-containing nanocomposites for versatile applications [44-46]. ANF/PEO [47] and ANF/PP [48] nanocomposite films with high mechanical strength and $\mathrm{Li}^{+}$ ion conductivity have been prepared as separators in the traditional organic liquid electrolyte-based LIBs, because of the effective prevention of Li dendrites [47,48], and the inhibition of the PEO crystallization by the hydrogen bond interactions between the ANFs and PEO [47]. As another aromatic polyamide with meta-type benzeneamide linkages in its skeletal chain, $\operatorname{poly}(m$-phenylene isophthalamide) (PMIA) has also been prepared as separators with great improvements in thermostability and electrochemical stability [49]. We have fabricated 3D porous ANF films with high mechanical, thermal and chemical stabilities by spin coating of the ANF dispersion [41], and different nanocomposite films of ANF/Au (Ag) $[42,50]$ and ANF/polyaniline (PANi) [51] with 3D ANF frameworks by filling $\mathrm{Au}(\mathrm{Ag})$ nanoparticles and PANi into the 3D porous ANF films, respectively. Thus, porous ANF films can be facilely fabricated and further utilized as attractive $3 \mathrm{D}$ scaffolds to acquire high-performance CPE membranes for Li metal batteries, while it has not yet fully elucidated in the literature.

Here, a facile, low-cost and scalable method is developed to prepare 3D porous ANF films by scraper coating of the ANF dispersion and subsequent drying (Fig. 1a), with the assistance of the hydrogen bond interactions between the amide groups in the ANFs (Fig. 1b). 3D ANF scaffold-supported CPE membranes were then fabricated by filling PEO-lithium bis(trifluoromethylsulphonyl) imide (LiTFSI) electrolyte into the porous ANF films via vacuum filtration or dripping (Fig. 1a). Owing to the high-strength 3D ANF networks, the CPE membranes were expected to show high flexibility, mechanical strength, thermostability and electrochemical stability. The hydrogen bond interactions between the ANFs, the PEO and TFSI would inhibit the PEO crystallization, weaken the ion-dipole or coordination interaction between PEO and $\mathrm{Li}^{+}$cations and facilitate the LiTFSI dissociation (Fig. 1c), and thereby lead to continuous $\mathrm{Li}^{+}$ion transport pathways at the 3D ANF framework/PEOLiTFSI interfaces (Fig. 1d).

As demonstrated by various characterizations such as scanning electron microscopy (SEM) and electrochemical impedance spectroscopy (EIS), the 3D ANF frameworkbased CPE membranes display greatly enhanced mechanical properties, thermostability, electrochemical stability and $\mathrm{Li}^{+}$ion conductivity, and therefore exhibit significantly improved interfacial resistance against $\mathrm{Li}$ 


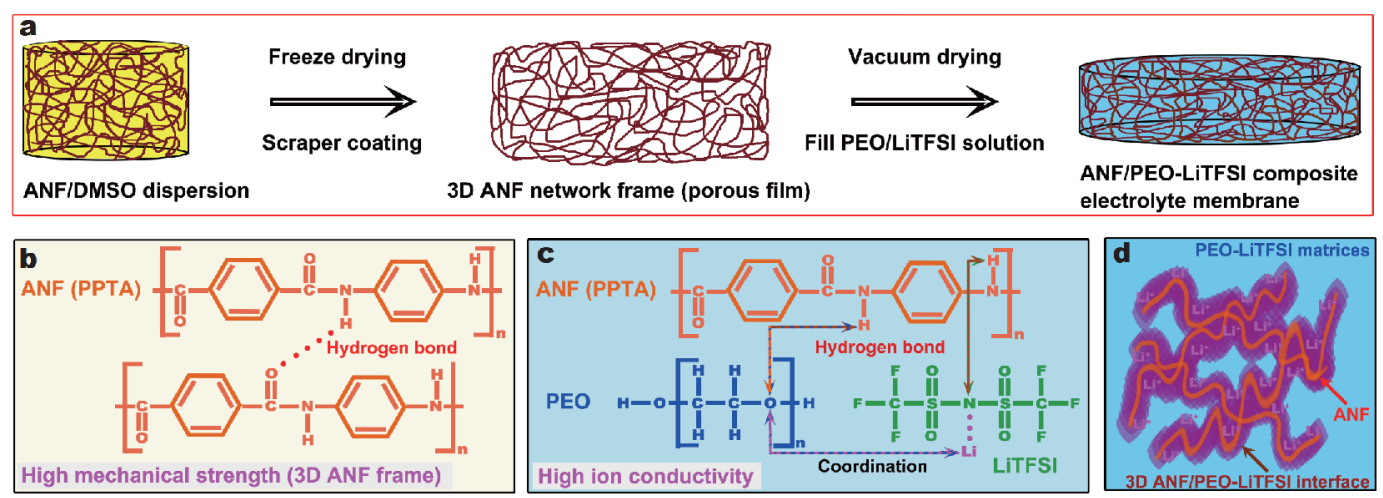

Figure 1 (a) Schematic illustration of the preparation of ANF/PEO-LiTFSI composite electrolyte membranes. (b) The hydrogen bond interaction between the amide groups of the ANFs. (c) The interactions between the ANF, PEO and LiTFSI. (d) The structure of the ANF framework-supported PEO-LiTFSI electrolytes.

dendrites (Tables S1-4). Additionally, the CPE-based allsolid-state $\mathrm{LiFePO}_{4} / \mathrm{Li}$ cells show superior cycling performance than the pristine PEO-LiTFSI electrolyte-based cell and even other CPE-based cells reported recently (Table S5). Hence, this work offers a facile and effective way to fabricate high-performance composite electrolytes with 3D scaffold design for potential Li metal battery applications.

\section{EXPERIMENTAL SECTION}

\section{Preparation of ANF/PEO-LiTFSI CPE membranes}

The ANF dispersion was synthesized by modifying our previously reported method [41,42,50]. Specifically, $200.0 \mathrm{~g}$ of dimethylsulfoxide (DMSO), $1.0 \mathrm{~g}$ of $\mathrm{KOH}$ and $2.0 \mathrm{~g}$ of bulk Kevlar 69 were put in a glass bottle with a cap for sealing, and vigorously stirred for 4 weeks until complete dissolution of the microfibers. To prepare 3D porous ANF films, the ANF/DMSO dispersion was coated on clean glass slides by a scraper, immersed in deionized water for three times and then a mixture solution of water and isopropanol $(1: 1, v / v)$, and finally freeze dried for at least $12 \mathrm{~h}$ until complete desiccation. The mixture solution of PEO and LiTFSI was prepared by dissolving $1.83 \mathrm{~g}$ of PEO (molecule weight: 400,000 ) and $0.66 \mathrm{~g}$ of LiTFSI in $30 \mathrm{~mL}$ acetonitrile at $60^{\circ} \mathrm{C}$ for $6 \mathrm{~h}$. This solution concentration was optimized to effectively fill the pores of the porous ANF films (Fig. S1). The ANF/ PEO-LiTFSI CPE membranes with different ANF contents of 7.7 and $10.9 \mathrm{wt} \%$ were fabricated by filling the $\mathrm{PEO} / \mathrm{LiTFSI} /$ acetonitrile solution in the porous ANF films by vacuum filtration and dripping, respectively, and then dried in vacuum condition at $40^{\circ} \mathrm{C}$ for $24 \mathrm{~h}$. The $\mathrm{CPEs}$ prepared by vacuum filtration and dripping were represented as ANF/PEO-FF and ANF/PEO-DF, respectively. The PEO-LiTFSI electrolyte film was obtained by dropping the $\mathrm{PEO} / \mathrm{LiTFSI} /$ acetonitrile solution with $0.92 \mathrm{~g}$ of PEO and $0.33 \mathrm{~g}$ of LiTFSI in a Teflon plate and then desiccated at $40^{\circ} \mathrm{C}$ for $24 \mathrm{~h}$ in vacuum condition. All the films were stored in an argon-filled glove box for at least 3 days before different characterizations.

\section{Characterizations}

The crystal structure of the electrolyte films were detected by a Bruker D8 Focus X-ray diffraction (XRD) analyzer ( $\mathrm{Cu} \mathrm{Ka}$ radiation, $\lambda=0.154 \mathrm{~nm}$ ). The microstructure and morphology of the ANFs and electrolytes were characterized by an FEI F20 transmission electron microscope (TEM) and a Hitachi SU8010 scanning electron microscope (SEM) coupled with an energy dispersive X-ray spectroscopy (EDS). The applied voltages for taking SEM and EDS images were 3.0 and $20.0 \mathrm{kV}$, respectively. A PerkinElmer Frontier Fourier transform infrared (FTIR) spectroscopy analyzer was used to obtain the FTIR absorbance spectra of the electrolyte films. A GOTECH AI7000-ST mechanical tester was applied to measure the mechanical tensile properties of the electrolyte films with a speed of $2 \mathrm{~mm} \mathrm{~min}^{-1}$. The thermal stability of the electrolytes was tested by using a D840TA Q500 thermogravimetric analyzer (TGA) in argon flow with a heating speed of $10^{\circ} \mathrm{C} \mathrm{min}^{-1}$.

\section{Electrochemical measurements}

The cells with different configurations of stainless steel (SS)/SPE/SS, Li/SPE/SS, Li/SPE/Li and $\mathrm{LiFePO}_{4} / \mathrm{SPE} / \mathrm{Li}$ were assembled in an argon-filled glove box for various electrochemical measurements. The $\mathrm{LiFePO}_{4}$ cathodes with a mass loading of $\sim 2.0 \mathrm{mg} \mathrm{cm}^{-2}$ were prepared by 
scraper coating of a mixture slurry of $\mathrm{LiFePO}_{4}$, poly(vinylidene fluoride) (PVDF), carbon black and carbon nanotube (8:1:0.97:0.03, wt/wt) on clean $\mathrm{Al}$ foils and followed by vacuum desiccation at $60^{\circ} \mathrm{C}$ for $24 \mathrm{~h}$. Linear sweep voltammetry (LSV) measurements were conducted in a CHI660E electrochemical workstation with a scanning rate of $1 \mathrm{mV} \mathrm{s}^{-1}$. A Zahner Zennium electrochemical workstation was utilized to obtain the electrochemical impedance spectroscopy (EIS) in a frequency range of $10^{6}-10^{-2} \mathrm{~Hz}$. The ionic conductivity $(\sigma)$ of the electrolytes was calculated based on the equation: $\sigma=L / S R$, where $R, L$ and $S$ were the resistance, thickness and surface area of the electrolyte films, respectively [38]. The cells were kept at each measurement temperature $\left(30-80^{\circ} \mathrm{C}\right)$ for $1.0 \mathrm{~h}$ for thermal equilibrium prior to the EIS measurements. $\mathrm{Li}^{+}$ ion transference number $\left(t_{\mathrm{Li}}{ }^{+}\right)$of the electrolytes was obtained by the combined measurements of EIS and chronoamperometry (CA) of the $\mathrm{Li} / \mathrm{SPE} / \mathrm{Li}$ cells at $80^{\circ} \mathrm{C}$. $t_{\mathrm{Li}}{ }^{+}$was calculated by using the classic equation: $t_{\mathrm{Li}}{ }^{+}=$
$I^{\mathrm{s}}\left(\Delta V-I^{0} R_{\mathrm{i}}^{0}\right) / I^{0}\left(\Delta V-I^{\mathrm{s}} R_{\mathrm{i}}^{\mathrm{s}}\right)$, where $I^{0}$ and $I^{\mathrm{s}}$ were the currents at the initial and steady states, respectively, $\Delta V$ was the applied direct current (DC) polarization potential of $10 \mathrm{mV}$, and $R_{\mathrm{i}}^{\mathrm{o}}$ and $R_{\mathrm{i}}^{\mathrm{s}}$ were the electrolyte/Li metal interface resistances at the initial and steady states, respectively [11,52]. Galvanostatic charge-discharge tests were conducted in a Land LANHE CT2001A multichannel battery tester between $2.5-3.8 \mathrm{~V}$ under various operation temperatures and $\mathrm{C}$ rates $\left(1 \mathrm{C}=170 \mathrm{~mA} \mathrm{~h} \mathrm{~g}^{-1}\right)$.

\section{RESULTS AND DISCUSSION}

\section{Morphology and microstructure}

The ANF dispersion is viscous and dark red after the complete dissolution of the microscale Kevlar fibers in DMSO (Fig. 2a). The ultra-long ANFs have a small mean diameter of $\sim 15 \mathrm{~nm}$, with a high aspect ratio (Fig. 2c). The ANFs were then employed to prepare 3D porous ANF films by the conventional blade coating technology
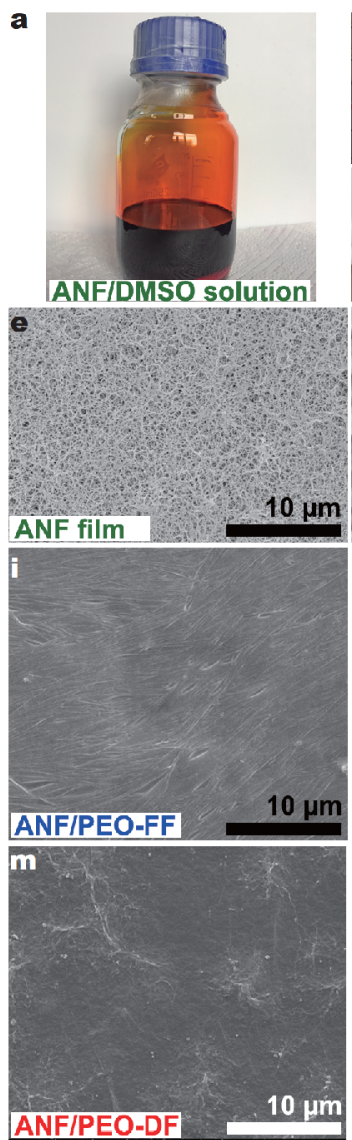
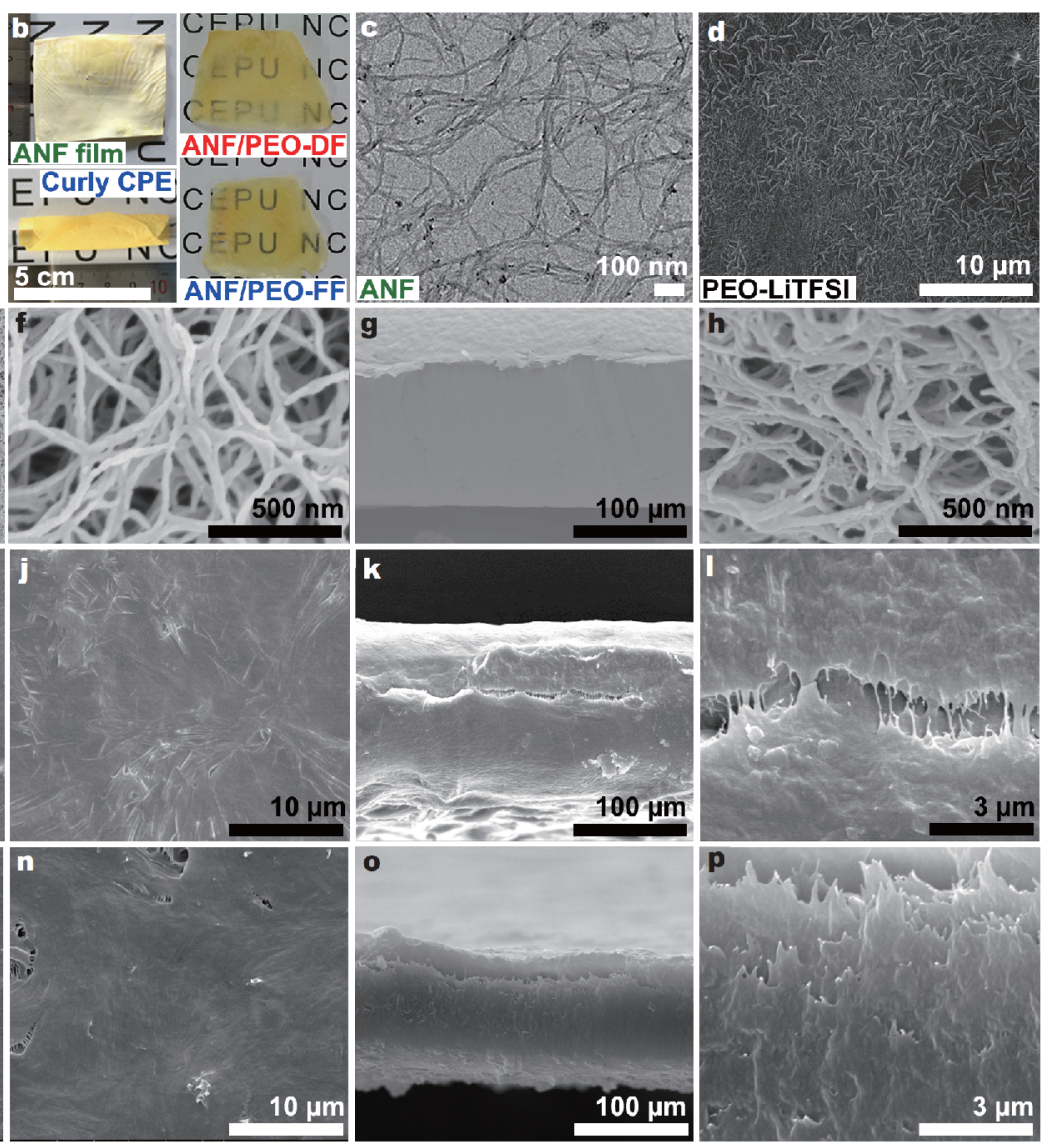

Figure 2 Optical images of (a) the ANF/DMSO solution, and (b) the 3D porous ANF film and the ANF/PEO-DF and ANF/PEO-FF composite electrolyte membranes. (c) TEM image of the ANFs. (d) Surficial SEM image of the PEO-LiTFSI electrolyte film. (e, f) Surficial and (g, h) crosssectional SEM images of the 3D porous ANF film. (i) Top-view, (j) back-view, and (k, l) cross-sectional SEM images of the ANF/PEO-FF CPE membrane. (m) Top-view, (n) back-view, and (o, p) cross-sectional SEM images of the ANF/PEO-DF CPE membrane. 
usually utilized to fabricate battery electrodes (Fig. 2b). The porous ANF films ( $129 \mu \mathrm{m}$ in thickness) are nontransparent with many uniform nano-pores (Fig. 2e-h), due to the strong hydrogen bond interactions between the $-\mathrm{NH}$ and $-\mathrm{C}=\mathrm{O}$ groups in the PPTA chains and the resulting interconnection of the ultralong ANFs [41]. The hydrogen bond interactions also lead to the increasing average diameter $(\sim 36 \mathrm{~nm})$ of ANF by merging the adjacent fibers.

After the infiltration of the PEO-LiTFSI electrolyte, the ANF films became transparent and the color also changed (Fig. 2b). The obtained CPE membranes can be easily curled around a glass rod without rupture, indicating high flexibility of the CPE films. The mechanical tensile properties will be further discussed in the following. As shown in the SEM images at the top, back and cross section of the CPEs, almost all the void spaces of the 3D porous ANF films are filled by the PEO-LiTFSI electrolyte (Fig. 2i-l and $\mathrm{m}-\mathrm{p}$ ). The uniform distribution of the elements such as $\mathrm{C}, \mathrm{O}, \mathrm{N}$ and $\mathrm{F}$ in EDS mappings also manifested the effective incorporation of the PEO-LiTFSI electrolyte in the 3D ANF scaffold (Fig. S2). The ANF/ PEO-FF CPE membrane had a thickness of $\sim 134 \mu \mathrm{m}$ comparable to that of the 3D porous ANF film but larger than that of the ANF/PEO-DF CPE membrane $(\sim 116 \mu \mathrm{m}$, Fig. $2 \mathrm{~g}, \mathrm{k}$ and $\mathrm{o}$ ), due to the effective filling of the polymer electrolyte solution by vacuum filtration. The ANF/PEO$\mathrm{FF}$ and ANF/PEO-DF CPEs showed less wrinkles than the pristine PEO-LiTFSI electrolyte on the surfaces (Fig. $2 \mathrm{i}, \mathrm{j}, \mathrm{m}, \mathrm{n}$ and $\mathrm{d}$ ), implying the effective suppression of the PEO crystallization by the ANF frameworks [53]. We can see a lot of interconnected ANFs inside the CPEs at the cross sections (Fig. $2 \mathrm{k}, 1$ and o, p), compared with the pristine electrolyte (Fig. S3). Moreover, the ANF/ PEO-DF CPE film had a much denser ANF framework with the aggregation of the ANFs than the ANF/PEO-FF CPE film, because of the higher ANF filling content of $10.9 \mathrm{wt} \%$ than that of the ANF/PEO-FF CPE film (7.7 wt\%). The aggregation phenomenon could be also verified by the diameter change of the ANFs in the ANF/ PEO-FF $(\sim 62 \mathrm{~nm})$ and ANF/PEO-DF $(\sim 73 \mathrm{~nm})$ CPEs. The unique CPE design with various ANF frameworks would have important impacts on the electrolyte properties such as mechanical properties and ionic conductivity.

\section{Electrochemical, mechanical and thermal stabilities}

The electrochemical stability of the electrolytes was investigated by LSV measurements of the Li/SPE/SS coin cells. The PEO-LiTFSI electrolyte has oxidation potentials of around 4.6 and $4.1 \mathrm{~V}$ at 30 and $60^{\circ} \mathrm{C}$, respectively (Fig. 3a). In comparison, the CPEs with the ANF frameworks exhibited the elevated oxidation potentials of around 5.0 and $4.6 \mathrm{~V}$ at 30 and $60^{\circ} \mathrm{C}$, respectively, higher than that of the organic liquid and ether-based electrolytes [54]. Previous study has reported the much higher electrochemical stability of the meta-aramid separator than the PP separator [49]. The great improvement of the electrochemical stability of the CPEs should be ascribed to the incorporation of the high-stability ANF frameworks.

The mechanical tensile stress-strain curves of the electrolyte films are shown in Fig. 3b. The pristine PEOLiTFSI electrolyte membrane showed a low ultimate tensile strength of $0.2 \mathrm{MPa}$ with a tensile strain of $684.3 \%$. In stark contrast, the ANF/PEO-FF CPE membrane showed a much higher ultimate tensile strength of $5.3 \mathrm{MPa}$ with a lower strain of $32.1 \%$, owing to the incorporation of the ANF framework. Further, the ANF/ PEO-DF CPE membrane with higher ANF content exhibited the highest ultimate tensile strength of $10.0 \mathrm{MPa}$. The mechanical strength of the ANF framework-based $\mathrm{CPE}$ membranes was comparable to those of the commercial PP/PE separators and much higher than those of other nanoparticle-filled CPEs such as aluminosilicate nanoparticle [52], $\mathrm{Mg}_{2} \mathrm{~B}_{2} \mathrm{O}_{5}$ nanowire [55], g- $\mathrm{C}_{3} \mathrm{~N}_{4}$ nanosheet [56], and 3D PEO-grafted polyimide scaffold [5]. The ANF/PEO-DF and ANF/PEO-FF CPE membranes also exhibited greatly enhanced Young's modulus of 33.4 and 17.0 MPa, which were 83.5 and 42.5 times higher than that of the pristine PEO-LiTFSI electrolyte membrane $(0.4 \mathrm{MPa})$, respectively. The high mechanical strength and flexibility of the ANF framework-based CPE membranes can afford the curliness of the films around the glass rod without destruction (Fig. 2b).

The thermal stability of the electrolyte films was firstly determined by TGA test (Fig. 3c). Because of the integration of the 3D ANF frameworks with high-thermostability [41], the ANF/PEO-FF and ANF/PEO-DF CPEs also have higher decomposition temperatures at around 411 and $420^{\circ} \mathrm{C}$ than the PEO-LiTFSI electrolyte $\left(366^{\circ} \mathrm{C}\right)$, respectively. Two different decomposition processes (i.e., slow weight loss at around $90-130^{\circ} \mathrm{C}$, and rapid weight loss at around $130-220^{\circ} \mathrm{C}$ ) are in the TGA curves of the ANF/PEO-DF and ANF/PEO-FF electrolytes, in addition to the main decomposition process beginning at $\sim 350^{\circ} \mathrm{C}$. The weight loss of ANF/PEO-FF electrolyte is much more than that of the ANF/PEO-DF electrolyte at $\sim 150^{\circ} \mathrm{C}$. The slow weight loss at low temperatures of $\leq 100^{\circ} \mathrm{C}$ is ascribed to the evaporation of the absorbed $\mathrm{H}_{2} \mathrm{O}$ (due to the 

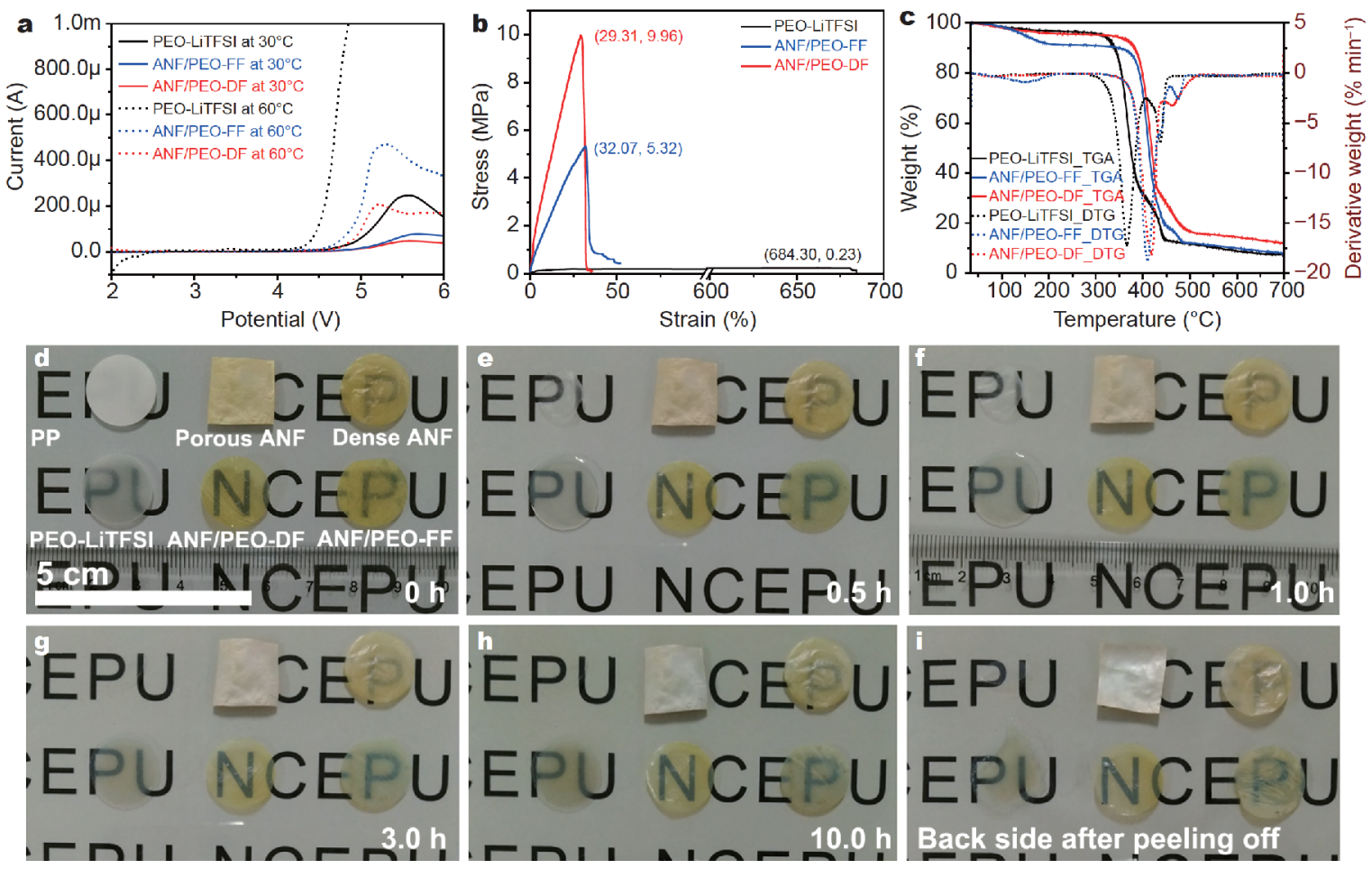

Figure 3 (a) LSV profiles, (b) mechanical tensile stress-strain curves, (c) TGA curves, and optical photographs at $160^{\circ} \mathrm{C}$ for (d) 0 , (e) 0.5 , (f) 1.0 , (g) 3.0 and (h) $10.0 \mathrm{~h}$ in an oven of the films. (i) Optical image of the films at the back side after peeling off from the glass substrate.

delayed TGA test); however, the weight loss is much more severe at $130-220^{\circ} \mathrm{C}$. This phenomenon also occurred in our previous studies (especially Fig. S4a) [39,44], and the aramid fiber size and the pore structure of the aramidbased films affected the thermo-decomposition behaviors. Besides, acetonitrile (used as solvent in this work) has much lower boiling point of $\sim 80^{\circ} \mathrm{C}$ and density of $\sim 0.8 \mathrm{~g} \mathrm{~cm}^{-3}$ than $\mathrm{H}_{2} \mathrm{O} \quad\left(\sim 100^{\circ} \mathrm{C}\right.$ and $\left.1.0 \mathrm{~g} \mathrm{~cm}^{-3}\right)$ at $0.1 \mathrm{MPa}$. Thus, the thermal process (decomposition at $\sim 150^{\circ} \mathrm{C}$ ) should be attributed to the change of the composite electrolyte structure, particularly of the ANF diameter (the average ANF size increased from $36 \mathrm{~nm}$ in the porous ANF film to $62 \mathrm{~nm}$ in the ANF/PEO-FF electrolyte and to $73 \mathrm{~nm}$ in the ANF/PEO-DF electrolyte, Fig. $2 \mathrm{e}-\mathrm{h}, \mathrm{k}, \mathrm{l}, \mathrm{o}, \mathrm{p})$. The aggregation/re-organization of the ANFs through the hydrogen bond interactions during the filling and drying procedures seemed to effectively enhance the thermostability and mechanical strength (Fig. $3 \mathrm{~b}, \mathrm{c})$ of the ANF/PEO-DF electrolyte.

Furthermore, the thermostability of the electrolyte films with circle shape was detected by observing the shape and color changes at $160^{\circ} \mathrm{C}$ in ambient environment (Fig. 3di). Similar to the commercial PP separator, the PEOLiTFSI electrolyte film easily melted after $0.5 \mathrm{~h}$ (Fig. 3e).
By contrast, the ANF/PEO-FF and ANF/PEO-DF CPE films maintained their original shape even after $10.0 \mathrm{~h}$ (Fig. 3h), due to the high thermostability of the ANF frameworks. The PEO-LiTFSI electrolyte film cannot be peeled off from the glass substrate after the heating test; however, the ANF films and the ANF-containing CPE films can be easily peeled off, further manifesting the high dimensional stability of the CPEs (Fig. 3i). The superior mechanical strength, thermostability and electrochemical stability of the ANF-containing CPEs would effectively procrastinate the nucleation of $\mathrm{Li}$ dendrites, and prohibit the crack formation in the polymer electrolytes when the Li dendrites permeated into the electrolytes $[27,57,58]$.

\section{Ion conductance}

The ion conductivity $(\sigma)$ can be calculated using the classic equation: $\sigma=\Sigma C_{\mathrm{i}} Q_{\mathrm{i}} \mu_{\mathrm{i}}$, where $C_{\mathrm{i}}$, $Q_{\mathrm{i}}$ and $\mu_{\mathrm{i}}$ represent the concentration, charge and mobility of the ions in the polymer electrolyte, respectively $[59,60]$. In typical polymer electrolyte systems, the dominated ion motions occur in the amorphous polymer regions through the local segmental motions, affecting the $\mathrm{Li}^{+}$ion mobility. Moreover, the interactions between the components in the polymer electrolytes would have an important impact 
on the free ion concentration and thus change the ion conductance.

As is known to all that the elements of $\mathrm{Li}, \mathrm{H}, \mathrm{S}, \mathrm{N}, \mathrm{Cl}, \mathrm{O}$ and $\mathrm{F}$ have the electronegativity values of $0.98,2.18,2.58$, $3.04,3.16,3.44$ and 3.98 , respectively. There is an iondipole or coordination interaction between the -Ogroups in PEO and the $\mathrm{Li}^{+}$ions in LiTFSI (Fig. 1c) [59]. It has been reported that the strong hydrogen bond interactions between the $-\mathrm{NH}$ groups in polyamides (e.g., PPTA) and the -O- groups in PEO can afford their layerby-layer assembly for composite membranes [46,61]. Other studies also show that calix[2]-p-benzo[4]pyrroles [62] and urea calis[4]arene [63,64] can effectively capture the anions of $\mathrm{Li}$ salts (e.g., $\mathrm{ClO}_{4}^{-}$) by the hydrogen bond interactions through their $-\mathrm{NH}$ groups, and emancipate more free $\mathrm{Li}^{+}$cations in the polymer electrolytes. Thus, the ANFs (more exactly, the -NH groups in PPTA) should have hydrogen bond interactions with the -Ogroups in PEO and the TFSI ${ }^{-}$anions in LiTFSI in theory (Fig. 1b), and have great influence on the polymer electrolytes (e.g., $C_{\mathrm{i}}$ or $\mu_{\mathrm{i}}$ of the $\mathrm{Li}^{+}$ion).

FTIR measurements were further conducted to analyze the hydrogen bond interactions between the ANFs and the PEO/LiTFSI matrices (Fig. 4a, b). The PEO-LiTFSI electrolyte showed a few typical absorbance peaks at around 842 and $1468 \mathrm{~cm}^{-1}$ and 788, 950, 1061, 1098 and $1348 \mathrm{~cm}^{-1}$, corresponding to the stretching/bending vibrations of the $\mathrm{C}-\mathrm{H}\left(\mathrm{CH}_{2}\right)$ and $\mathrm{C}-\mathrm{O}(\mathrm{C}-\mathrm{O}-\mathrm{C})$ groups of the $\mathrm{PEO}$ matrices, respectively $[65,66]$. Other absorbance peaks at around 568,740,763 and $1283 \mathrm{~cm}^{-1}$ related to the stretching vibrations of $\mathrm{CF}_{3}$ and $\mathrm{C}-\mathrm{F}$ groups in LiTFSI also appeared $[67,68]$. The characteristic peaks at around 653, 1187 and $1631 \mathrm{~cm}^{-1}$ were attributed to the S-O stretching, C-SO $\mathrm{S}_{2}-\mathrm{N}$ stretching and LiTFSI aggregation, respectively $[67,68]$. The obvious peaks at around 732 and 1517,1548 , and $1660 \mathrm{~cm}^{-1}$ were ascribed to the stretching/bending vibrations of the $\mathrm{N}-\mathrm{H}, \mathrm{C}-\mathrm{N}$, and $\mathrm{C}=\mathrm{O}$ in the 3D porous ANF film, respectively.

The interactions between the ANF nanofillers and the electrolyte matrices were investigated by analyzing the changes of the FTIR spectra. The decrease in the peak intensity and the peak shift of the $\mathrm{N}-\mathrm{H}$ bands from $732 \mathrm{~cm}^{-1}$ in the 3D porous ANF film to $708 \mathrm{~cm}^{-1}$ in the ANF-containing CPEs, and some other changes including the peak shape and position of the $\mathrm{C}-\mathrm{N}$ and $\mathrm{C}=\mathrm{O}$ bands together manifested the strong interactions between the
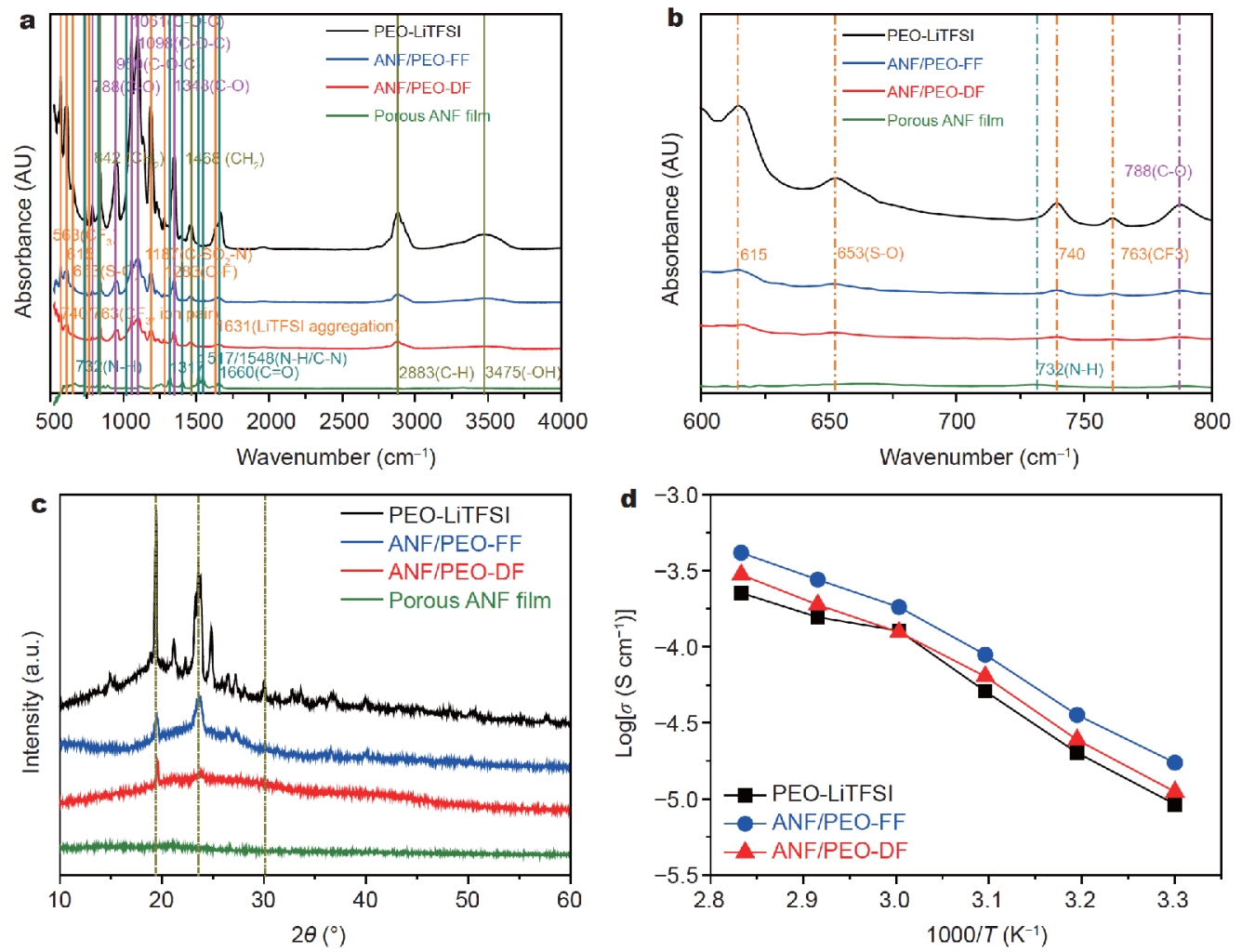

Figure 4 (a, b) FTIR spectra, and (c) XRD patterns of the porous ANF film and the electrolyte membranes. (d) Ionic conductivities of the electrolyte membranes. 
$\mathrm{PEO} / \mathrm{LiTFSI}$ matrices and the ANFs. In comparison with the PEO-LiTFSI electrolyte, the intensity, shape and position of the $\mathrm{C}-\mathrm{O}(\mathrm{C}-\mathrm{O}-\mathrm{C})$ vibration peaks also changed greatly in the CPEs. These obvious changes should be ascribed to the hydrogen bond interactions between the $\mathrm{C}-\mathrm{O}$ groups of the $\mathrm{PEO}$ and the $\mathrm{N}-\mathrm{H}$ groups of the ANFs, which would inhibit the PEO crystallization by perturbing the ordering of the PEO chains. The intensity of the typical peaks at around $19.5^{\circ}, 23.7^{\circ}$ and $30.1^{\circ}$ related to the PEO crystallinity [69] became weaker in the ANF-based CPEs (Fig. 4c), further proving the effective suppression of the PEO crystallization by the ANF frameworks. These results were consistent with the surficial SEM images of the electrolyte membranes regarding the wrinkles and roughness (Fig. 2i, j, m, n and d). The decrease of the PEO crystallization would lead to the accelerated local segmental motions in the amorphous regions, and the increase of the $\mathrm{Li}^{+}$ion mobility $\left(\mu_{\mathrm{i}}\right)$ by hopping along/between the PEO chains [59].

Furthermore, the CPEs showed lower intensity of the peaks at around 740 and $763 \mathrm{~cm}^{-1}$ than the PEO-LiTFSI electrolyte (Fig. 4a, b), suggesting that less triflate-containing anions were in pairs in the ANF-based electrolytes [68]. The intensity of the peak at around $1631 \mathrm{~cm}^{-1}$ with respect to the LiTFSI aggregation [67] also decreased greatly. On the basis of the elemental electronegativity values, FTIR analyses and reports from other researchers [62-64], we can easily deduce that the hydrogen bond interactions between the $-\mathrm{NH}$ groups in ANF and the TFSI $^{-}$anions (mainly the $\mathrm{F}$ atoms, because of the high $\mathrm{F}$ electronegativity and the F-related peak intensity change) resulted in the effective dissolution and dissociation of LiTFSI, which would increase the free ion concentration

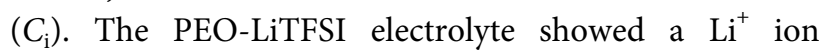
transference number of 0.24 (Fig. S5a, b), consistent with other reports of $0.2-0.3[9,25,50]$. In comparison, the ANF/PEO-FF and ANF/PEO-DF electrolytes had much higher $\mathrm{Li}^{+}$ion transference numbers of 0.47 (Fig. S5e, f) and 0.36 (Fig. S5c, d), respectively. This also suggested the effective immobilization or capture capability of the TFSI $^{-}$ anions by the ANF nanofillers through the hydrogen bond interaction, in accordance with the FTIR analyses (Fig. 4a, b). The lower $\mathrm{Li}^{+}$ion transference number of the ANF/PEO-DF electrolyte than that of the ANF/PEO-FF electrolyte should be attributed to the large aggregation of the ANF nanofillers in the ANF/PEO-DF electrolyte and the insufficient contact between the ANFs and the $\mathrm{PEO} /$ LiTFSI matrices (Fig. 2k, 1, o, p).

According to the ion conductivity equation: $\sigma=\Sigma C_{\mathrm{i}} \mathrm{Q}_{\mathrm{i}} \mu_{\mathrm{i}}$, increase of either $\mu_{\mathrm{i}}$ or $C_{\mathrm{i}}$ would increase the ion con- ductivity. As discussed above, the hydrogen bond interactions have multiple impacts on the electrolyte matrices: (1) the hydrogen bond between ANF and PEO can inhibit the PEO crystallization, accelerate the PEO chain motions, and therefore increase the $\mathrm{Li}^{+}$ion mobility $\left(\mu_{\mathrm{i}}\right) ;(2)$ the hydrogen bond between ANF and PEO can also weaken the coordination strength between the -Ogroups in $\mathrm{PEO}$ and the $\mathrm{Li}^{+}$cations and thus increase the free $\mathrm{Li}^{+}$cation concentration $\left(C_{\mathrm{i}}\right)$ on the ANF nanofiller surfaces [59,70]; (3) according to the classic Lewis acidbase theory, the hydrogen bond between ANF and TFSI in LiTFSI can capture the anions and release more free $\mathrm{Li}^{+}$cations (i.e., increase the $C_{\mathrm{i}}$ of the $\mathrm{Li}^{+}$ion) on the ANF nanofiller surfaces, leading to an expressway for $\mathrm{Li}^{+}$ion migration at the ANF/PEO-LiTFSI interfaces [71,72]; (4) the 3D ANF network formed by the ANF nanofillers through hydrogen bond interactions would further result in continuous ion conduction on the 3D ANF framework surface (Fig. 1d). Because of these synergistic effects of the ANF nanofillers on the PEO and LiTFSI, the PEO/ANFFF CPE membrane showed higher ionic conductivities of $1.7 \times 10^{-5}$ and $1.8 \times 10^{-4} \mathrm{~S} \mathrm{~cm}^{-1}$ than the pristine PEOLiTFSI electrolyte $\left(9.2 \times 10^{-6}\right.$ and $\left.1.3 \times 10^{-4} \mathrm{~S} \mathrm{~cm}^{-1}\right)$ at 30 and $60^{\circ} \mathrm{C}$, respectively (Fig. S6 and Fig. $4 \mathrm{~d}$ ). The $\mathrm{PEO} /$ ANF-DF CPE membrane also exhibited a decent roomtemperature conductivity of $1.1 \times 10^{-5} \mathrm{~S} \mathrm{~cm}^{-1}$. In stark contrast, the utilization of PP-based Celgard 2500 separator [40] and $\mathrm{SiO}_{2}$-based glass fiber [3] as 3D scaffolds was reported to reduce the ionic conductivity, possibly attributed to the poor interactions between these scaffolds and the electrolyte matrices or the large size of the scaffolds.

To explain the higher ionic conductivity $(\sigma)$ of the ANF/PEO-FF electrolyte (than that of the ANF/PEO-DF electrolyte), the activation energy $\left(E_{\mathrm{a}}\right)$ was calculated by the Arrhenius relationship equation: $\sigma=A \exp \left(-E_{\mathrm{a}} / R T\right)$, where $A, E_{\mathrm{a}}, R$ and $T$ represent the pre-exponential factor, activation energy, gas constant, and absolute temperature, respectively $[71,73]$. In the low-temperature range of 30$60^{\circ} \mathrm{C}$, the ANF/PEO-FF electrolyte showed lower activation energy of $64 \mathrm{~kJ} \mathrm{~mol}^{-1}$ than the ANF/PEO-DF $\left(72 \mathrm{~kJ} \mathrm{~mol}^{-1}\right)$ and PEO-LiTFSI $\left(77 \mathrm{~kJ} \mathrm{~mol}^{-1}\right)$ electrolytes, indicating the relatively fast ion migration [74] and lowenergy-barrier ion transport pathway in the ANF/PEO-FF electrolyte [66]. According to the ion conductivity equation: $\sigma=\Sigma C_{\mathrm{i}} \mathrm{Q}_{\mathrm{i}} \mu_{\mathrm{i}}$, the low crystallization of the ANF/PEODF electrolyte (Fig. 4c) implied the facilitated motion and ion mobility $\left(\mu_{\mathrm{i}}\right)$ of PEO chains, which would lead to the improved ion conductivity. However, the ionic conductivity was related to not only the mobility and con- 
centration of the ions, but also the ion transport pathways in the electrolyte [75]. The hydrogen bond interactions between the ANFs and PEO can not only suppress the PEO crystallization, but also weaken the coordination strength between the -O- groups in PEO and the $\mathrm{Li}^{+}$ cations to increase the free $\mathrm{Li}^{+}$ion concentration $\left(C_{\mathrm{i}}\right)$ on the ANF surfaces [59,70]. Compared with the ANF/PEOFF electrolyte, the ANFs aggregated more severely in the ANF/PEO-DF electrolyte (Fig. 2k, l, o, p), implying the limited contact areas between the ANFs and the $\mathrm{PEO} /$ LiTFSI matrices and less free ion concentration in the ANF/PEO-DF electrolyte. Moreover, the insufficient filling of the PEO-LiTFSI electrolyte by the dripping method caused the generation of the pores in the ANF/PEO-DF electrolyte (Fig. $2 \mathrm{~m}, \mathrm{n}$ ), and would result in the incontinuous ion transport and have detrimental effect on the ion conductivity. Besides, the excessive utilization of inert/low-conductivity nanofillers can decrease the ionic conductivity of the composite electrolytes. We have also proven the much lower ionic conductivity of the ANF (i.e., PPTA)-LiTFSI electrolyte $\left(9.2 \times 10^{-8} \mathrm{~S} \mathrm{~cm}^{-1}\right.$ at $30^{\circ} \mathrm{C}$, Fig. S7), consistent with other reports on the rigid amidebenzene backbone-based polymer electrolytes [76-78]. The high ANF content in the ANF/PEO-DF electrolyte (10.9 wt\% vs. 7.7 wt $\%$ ANF in the ANF/PEO-FF electrolyte) may be adverse to the ionic conductivity. Previous studies have also verified that the excessive addition of nanofillers into the polymer matrices resulted in the aggregation and free-volume depletion of the nanofillers and the reduction of the ionic conductivity $[55,69,79]$. Overall, the lower ionic conductance of the ANF/PEO-DF electrolyte should be attributed to the agglomeration of the ANFs, generation of the pores, and the high content of the inert/low-conductivity ANFs in the ANF/PEO-DF electrolyte. This also indicated that the ionic conductivity of the ANF/PEO-FF electrolyte can be further elevated by inhibiting the ANF aggregation via optimizing the filling method, because the average ANF diameter also increased from $36 \mathrm{~nm}$ (in the porous ANF film) to $62 \mathrm{~nm}$ (in the ANF/PEO-FF electrolyte).

\section{Interfacial resistance against $\mathrm{Li}$ dendrites}

The mechanical resistance of the electrolyte films against Li dendrites was vital to their practical implementations in Li metal batteries, and thus was scrutinized in the Li/ SPE/Li cell configuration. During the periodic chargedischarge cycling processes, $\mathrm{Li}^{+}$ions were alternatively stripping and plating on the Li metal electrodes, which may cause the formation/growth of $\mathrm{Li}$ dendrites and the destruction of the electrolyte films. The cells were first electrochemically cycled at a high temperature of $60^{\circ} \mathrm{C}$ under various current densities of $0.025-0.50 \mathrm{~mA} \mathrm{~cm}^{-2}$ (Fig. 5a, b and Fig. S8a). The over-potential of all the cells increased with the increase of the current density. Specifically, the over-potential of the PEO-LiTFSI electrolytebased cell increased from $0.1256 \mathrm{~V}$ at $0.05 \mathrm{~mA} \mathrm{~cm}^{-2}$ to $1.3935 \mathrm{~V}$ at $0.50 \mathrm{~mA} \mathrm{~cm}^{-2}$, and then decreased to $0.0552 \mathrm{~V}$ when the current density returned to $0.05 \mathrm{~mA} \mathrm{~cm}^{-2}$ after $200 \mathrm{~h}$ (Fig. 5a). In comparison, both the cells with the ANF/PEO-FF and ANF/PEO-DF CPEs exhibited much lower over-potentials (e.g., around $0.1 \mathrm{~V}$ at $0.50 \mathrm{~mA} \mathrm{~cm}^{-2}$, Fig. $5 \mathrm{~b}$ and Fig. S8a), reflecting the lower interfacial resistance between the ANF-containing electrolytes and the Li metal electrodes.

The cells were then galvanostatically cycled at a lower temperature of $30^{\circ} \mathrm{C}$ with a charge-discharge cycle of 10 min (Fig. 5c, d and Fig. S8b). The ANF-containing cells also exhibited much lower over-potentials of around $0.2 \mathrm{~V}$ than the ANF-free cells (around $0.9 \mathrm{~V}$ after $500 \mathrm{~h}$ ) during the long-term cycling. Moreover, the continuous decrease of the over-potential of the cells was ascribed to the improved interfacial contact between the Li metal electrodes and the electrolyte films [30]. Further, the charge-discharge time was increased to $60 \mathrm{~min}$ per cycle to observe the cycling stability (Fig. 5e, f and Fig. S8c). The PEO-LiTFSI electrolyte-based cell showed high potentials up to around $4 \mathrm{~V}$, and short circuits (i.e., sudden potential drop to $\sim 0 \mathrm{~V}$ ) also occurred in the first $2 \mathrm{~h}$ (Fig. 5e), implying the piercing of the electrolyte film by the $\mathrm{Li}$ dendrites $[80,81]$. The following charging and discharging with the flux of the overpotential could be attributed to the non-zero resistance of the Li dendrites [82] and the continuous formation of passivation layers [83]. In distinct contrast, no short circuits occurred in both the ANF-containing cells, and the over-potentials almost kept at around $0.4 \mathrm{~V}$ during the whole cycling (Fig. $5 \mathrm{f}$ and Fig. $\mathrm{S} 8 \mathrm{c}$ ), again verifying the dual and positive effects of the ANF frameworks on the mechanical strength and interfacial resistance, consistent with the mechanical tensile and ionic conductivity results (Figs $3 \mathrm{~b}$ and $4 \mathrm{~d}$ ). It should be noted that not only the increase of the charge/discharge time (from 10 to $60 \mathrm{~min}$ per cycle, Fig. $5 \mathrm{c}-\mathrm{f}$ ), but also other factors such as the high current density (from 0.025 to $0.50 \mathrm{~mA} \mathrm{~cm}^{-2}$, Fig. 5a, b) and low operation temperature (from 60 to $30^{\circ} \mathrm{C}$, Fig. $5 \mathrm{a}-\mathrm{d}$ ) can cause the overpotential increase of the cells due to the resistance change $[3,15,30,36,84]$. It was also interesting to disclose the impact of the charge/discharge condition on the Coulombic efficiency (CE) of the cells (Fig. S9). All the cells showed a similar CE of $100 \pm 5 \%$ when increasing 

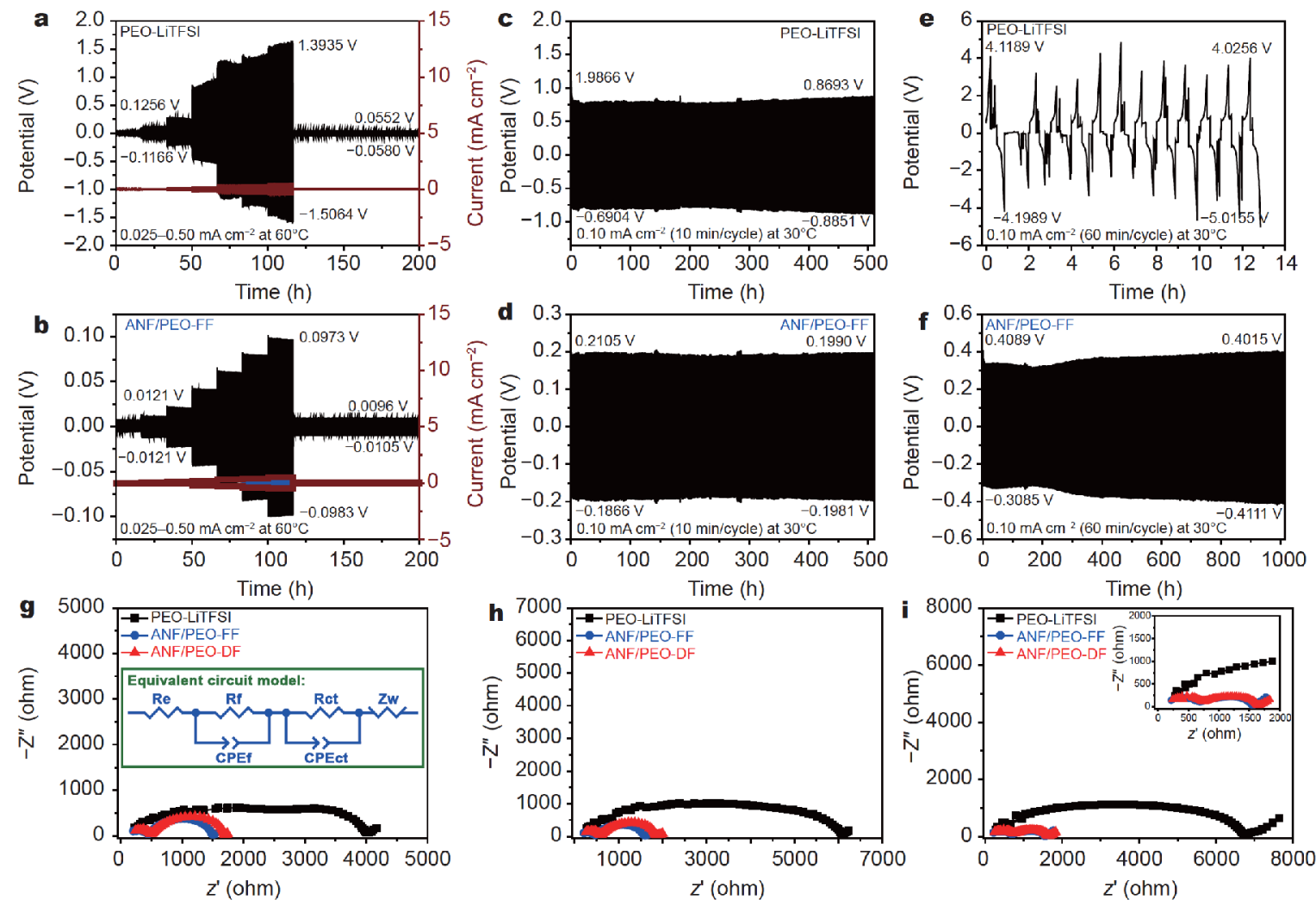

Figure 5 Galvanostatic cycling curves of the (a, $c$ and e) PEO-LiTFSI and (b, d and f) ANF/PEO-FF electrolyte-based Li/Li cells under (a, b) various current densities of $0.025-0.50 \mathrm{~mA} \mathrm{~cm}^{-2}$ for $200 \mathrm{~h}$ at $60^{\circ} \mathrm{C},(\mathrm{c}, \mathrm{d}) 0.10 \mathrm{~mA} \mathrm{~cm}$ with the charge-discharge time of $10 \mathrm{~min}$ per cycle for $500 \mathrm{~h}$ at $30^{\circ} \mathrm{C}$, and (e, f) $0.10 \mathrm{~mA} \mathrm{~cm}{ }^{-2}$ with the charge-discharge time of $60 \mathrm{~min}$ per cycle for $1000 \mathrm{~h}$ at $30^{\circ} \mathrm{C}$. EIS spectra of the Li/Li cells at $30^{\circ} \mathrm{C}(\mathrm{g})$ before and after the galvanostatic cycling under (h) $0.10 \mathrm{~mA} \mathrm{~cm}^{-2}$ for $500 \mathrm{~h}$ with the charge-discharge time of 10 min per cycle and then under (i) $0.10 \mathrm{~mA} \mathrm{~cm}$ for $1000 \mathrm{~h}$ with the charge-discharge time of $60 \mathrm{~min}$ per cycle (an equivalent circuit model was given in Fig. $5 \mathrm{~g}$ ).

the current density from 0.025 to $0.50 \mathrm{~mA} \mathrm{~cm}^{-2}$ at $60^{\circ} \mathrm{C}$, and the $\mathrm{CE}$ fluctuated more severely when returning to $0.05 \mathrm{~mA} \mathrm{~cm}^{-2}$ again (Fig. S9a). The cells also exhibited the similar $\mathrm{CE}$ of $\sim 100 \%$ when cycled at $30^{\circ} \mathrm{C}$ and $0.10 \mathrm{~mA} \mathrm{~cm}^{-2}$ with the charge/discharge time of $10 \mathrm{~min}$ per cycle (Fig. S9b). With increasing charge/discharge time to 60 min per cycle, the PEO-LiTFSI electrolytebased cell had the increasing overpotential of $\sim 5.0 \mathrm{~V}$ at the 13th cycle (Fig. 5e) and then stopped with a low CE of 74\% (Fig. S9c); however, the ANF-based cells had relatively stable and high CEs of $\sim 100 \%$ during the long-term cycling.

The impedance change of the Li/SPE/Li cells during the Li stripping/plating processes was investigated by the EIS technology (Fig. 5g-i and Fig. S10). The semicircles at high and low frequencies were related to the ohmic resistance from the electrolytes $\left(R_{\mathrm{e}}\right)$ and the SPE/Li interfacial resistance $\left(R_{\mathrm{i}}\right)$, respectively $[30,69,80]$. The interfacial resistance contained two parts, i.e., the resistance resulting from the electrolyte decomposition $\left(R_{\mathrm{f}}\right)$ and the charge transfer resistance $\left(R_{\mathrm{ct}}\right)$ [85]. The fitted data were given in Tables S1-3. During the first cycling at various rates of $0.025-0.50 \mathrm{~mA} \mathrm{~cm}^{-2}, 60^{\circ} \mathrm{C}$, the total resistances of the cells based on the ANF/PEO-FF, ANF/ PEO-DF and PEO-LiTFSI electrolytes decreased from 223, 259 and $867 \mathrm{ohm}$ to 138,233 and $426 \mathrm{ohm}$ at $60^{\circ} \mathrm{C}$, respectively (Fig. S10 and Table S1), indicating the improved interfacial contact between the SPEs and Li metal electrodes upon the cycling $[30,69,80]$. This also led to the decreasing overpotentials of the $\mathrm{Li} / \mathrm{SPE} / \mathrm{Li}$ cells $\left(0.05 \mathrm{~mA} \mathrm{~cm}^{-2}\right.$, Fig. 5a, b and Fig. S8a). Furthermore, when cycled at $0.10 \mathrm{~mA} \mathrm{~cm}^{-2}, 30^{\circ} \mathrm{C}$, the total resistance of the PEO-LiTFSI electrolyte-based cell increased from 4058 to $6897 \mathrm{ohm}$, which was much higher than those of the PEO/ANF-FF (from 1524 to $1574 \mathrm{ohm}$ ) and the PEO/ ANF-DF (from 1735 to $1671 \mathrm{ohm}$ ) CPE-based cells (Fig. 5g-i and Tables S2, 3). This explained why the ANFcontaining cells exhibited relatively low and stable overpotentials, and also manifested the higher interfacial stability of the ANF-containing CPEs than the pristine 
PEO-LiTFSI electrolyte.

The surficial microstructure of the electrolyte films after the long-time galvanostatic cycling was further detected by SEM (Fig. S11). We can clearly see that many dendrites formed on the PEO-LiTFSI electrolyte surface (Fig. S11a-c), which should be the reason of the short circuit of the Li/SPE/Li cell during the galvanostatic cycling (Fig. 5e). In stark contrast, no Li dendrite was found on both the ANF/PEO-FF and ANF/PEO-DF CPE membrane surfaces (Fig. S11d-f and g-i), again proving the superior interfacial resistance against $\mathrm{Li}$ dendrite formation by the ANF framework-supported CPE films. These electrochemical results agreed well with the abovementioned discussion that the high mechanical strength and thermostability can delay the nucleation of the $\mathrm{Li}$ dendrite and inhibit the dendrite growth in the electrolytes [32,57]. Moreover, the dendrite formation time $(\tau)$ was calculated with the equation $\tau=\pi D\left(C_{0} e\right)$ $\left.2 J t_{\mathrm{a}}\right)^{2}$, where $J, C_{\mathrm{o}}, D$ and $t_{\mathrm{a}}$ are the current density, initial ion concentration, diffusion constant and anion transference number, respectively $[86,87]$. The ANF framework-based CPEs had much higher $\mathrm{Li}^{+}$ion transference numbers than the PEO-LiTFSI electrolyte (Fig. S5), which can effectively mediate the space charge at the electrolyte/ electrode interfaces, eliminate the concentration polarization and delay the dendrite generation, and thereby result in less dendrites $[58,88,89]$.

\section{All-solid-state Li metal battery performance}

As described above, the 3D ANF framework-supported CPEs showed comprehensively improved properties of mechanical strength, thermostability, electrochemical stability, ion conductivity, and interfacial resistance against Li dendrites (Table S4). To examine their practical implementations in $\mathrm{Li}$ metal batteries, all-solid-state $\mathrm{LiFePO}_{4} / \mathrm{SPE} / \mathrm{Li}$ cells were then fabricated and tested. When cycled at $0.1 \mathrm{C}$, the capacity of all the cells increased with the operation temperature increase (Fig. 6a), owing to the increasing $\mathrm{Li}^{+}$ion conductivity (Fig. $4 \mathrm{~d}$ ). The ANF/PEO-FF CPE-based cell also showed higher capacities of $94,155,159,159,160$ and $158 \mathrm{~mA} \mathrm{~h} \mathrm{~g}^{-1}$ than the ANF/PEO-DF (47, 117, 146, 148, 150 and $149 \mathrm{~mA} \mathrm{~h} \mathrm{~g}^{-1}$ ) and PEO-LiTFSI $\left(18,71,112,124,131\right.$ and $\left.134 \mathrm{~mA} \mathrm{~h} \mathrm{~g}^{-1}\right)$ electrolyte-based cells at $30,40,50,60,70$ and $80^{\circ} \mathrm{C}$, respectively.

When cycled at $60^{\circ} \mathrm{C}$ under various $\mathrm{C}$ rates, both the ANF-based cells showed much higher capacities than the ANF-free cell (Fig. 6b-d and Fig. S12a). Specifically, the ANF/PEO-FF CPE-based cell had higher capacities of $149,155,152,146$ and $96 \mathrm{~mA} \mathrm{~h} \mathrm{~g}^{-1}$ than the ANF/PEO-
DF $\left(134,144,138,120\right.$ and $\left.77 \mathrm{~mA} \mathrm{~h} \mathrm{~g}^{-1}\right)$ and PEO-LiTFSI $\left(129,135,129,100\right.$ and $53 \mathrm{~mA} \mathrm{~h} \mathrm{~g}^{-1}$ ) electrolyte-based cells at $0.1,0.2,0.3,0.5$ and $1.0 \mathrm{C}$, respectively. The increasing capacity with the increase of the current density from 0.1 to $0.2 \mathrm{C}$ may be attributed to the enhanced interfacial contact between the SPEs and the electrodes and the activation of the $\mathrm{LiFePO}_{4}$ [69]. After the return of the current density to $0.1 \mathrm{C}$ again, the ANF/PEO-FF CPEbased cell also exhibited higher capacity of $147 \mathrm{~mA} \mathrm{~h} \mathrm{~g}^{-1}$ with a retention rate of $99 \%$ than the ANF/PEO-DF $\left(134 \mathrm{~mA} \mathrm{~h} \mathrm{~g}^{-1}\right)$ and PEO-LiTFSI $\left(128 \mathrm{~mA} \mathrm{~h} \mathrm{~g}^{-1}\right)$ electrolyte-based cells.

The long-term cycling stability of the cells was also examined (Fig. 6e-i and Fig. S12b). The ANF/PEO-FF CPE-based cell displayed higher capacity of $130 \mathrm{~mA} \mathrm{~h} \mathrm{~g}^{-1}$ and capacity retention of $93 \%$ than the ANF/PEO-DF $\left(120 \mathrm{~mA} \mathrm{~h} \mathrm{~g}^{-1}\right.$ and $\left.87 \%\right)$ and PEO-LiTFSI $\left(82 \mathrm{~mA} \mathrm{~h} \mathrm{~g}^{-1}\right.$ and 66\%) electrolyte-based cells after 100 cycles at $0.4 \mathrm{C}$ and $60^{\circ} \mathrm{C}$ (Fig. $6 \mathrm{~g}$ ). The greatly improved battery performance should be attributed to the comprehensively enhanced properties of mechanical strength, thermostability, electrochemical stability, ion conductance and interfacial stability against $\mathrm{Li}$ dendrites by the multifunctional ANF frameworks (Table S4). Even compared with the all-solid-state cells with other nanoadditivefunctionalized CPEs, the ANF/PEO-FF CPE-based cell still exhibited superior cycling performance (Table S5). We can see the severe deformation of the charge/discharge curves in the PEO-LiTFSI electrolyte-based cell (Fig. 6e), also reported in other studies [90,91]. The cell displayed two typical platforms at $\sim 3.5 \mathrm{~V}$ in the charge state and at $\sim 3.4 \mathrm{~V}$ in the discharge state at a low current density of $0.1 \mathrm{C}$; however, the charge/discharge curves began to change or deform at $0.2 \mathrm{C}$, and the deformation was much more severe at 0.3 and $0.5 \mathrm{C}$ (Fig. 6b). The deformation was quite similar to that in Fig. 6e (at $0.4 \mathrm{C}$ ). The deformation of the charge/discharge curves caused the great increase of the charge potential and the decrease of the discharge potential, and thus can be also regarded as a polarization behavior. Moreover, the deformation became more and more severe with increasing charge/ discharge cycle number or current density, consistent with the previous studies $[15,56,91,92]$. Actually the ANF/ PEO-FF and ANF/PEO-DF electrolyte-based cells also showed the similar yet non-severe deformation at high current densities of 0.5-1.0 C (Fig. 6c and Fig. S12). Based on these analyses and other reports on the high stability of the $\mathrm{LiFePO}_{4}$ cathodes [56,72], one can easily conclude that the deformation is not related to the $\mathrm{LiFePO}_{4}$ cathode but the electrolyte. Previous studies usually ascribed 

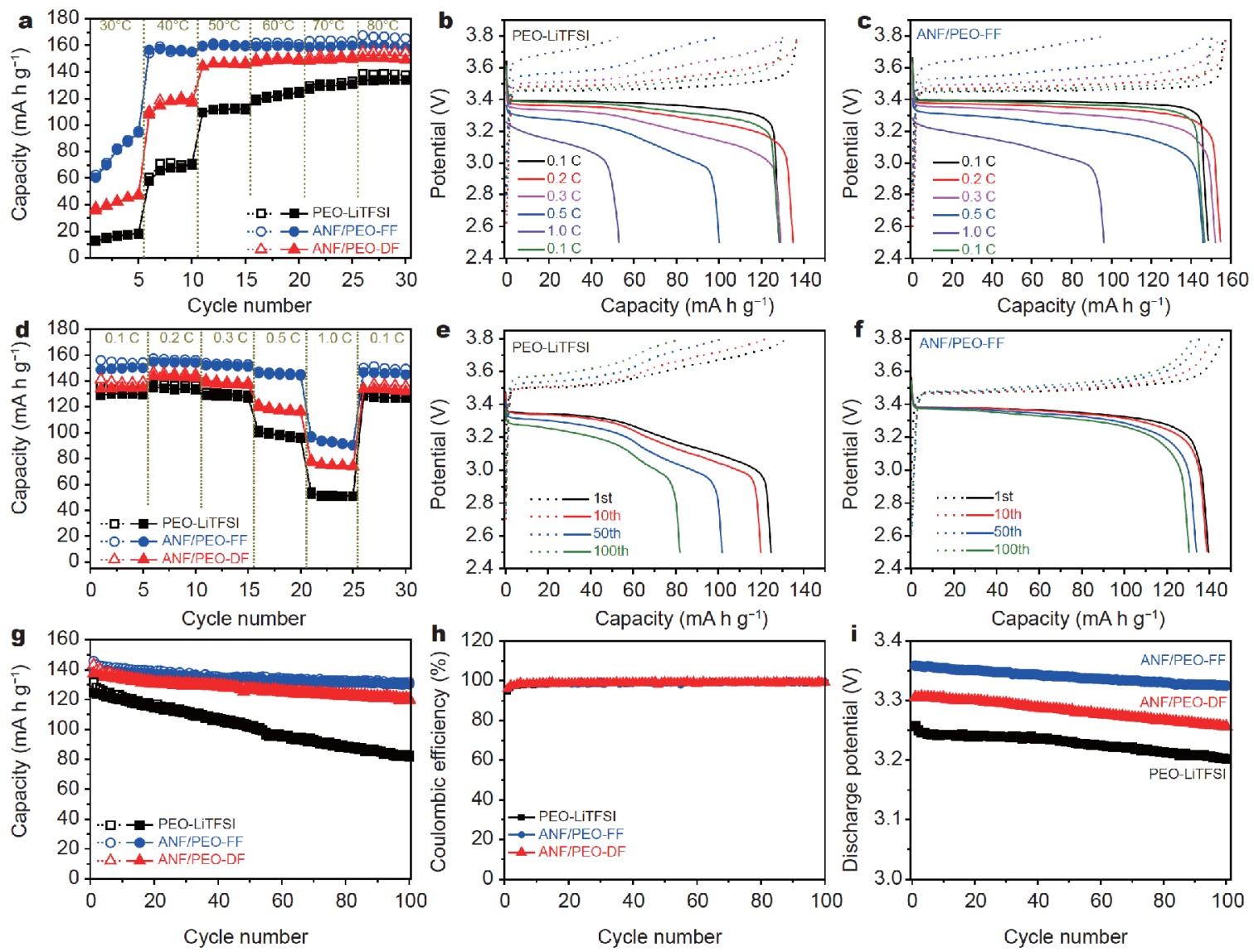

Figure 6 (a) Cycling performance of the solid-state $\mathrm{LiFePO}_{4} / \mathrm{Li}$ cells at $0.1 \mathrm{C}$ under various operation temperatures. Typical charge-discharge profiles of the solid-state cells using (b) PEO-LiTFSI and (c) ANF/PEO-FF electrolytes at $60^{\circ} \mathrm{C}$ and various current densities, respectively. (d) Rate performance of the solid-state $\mathrm{LiFePO}_{4} / \mathrm{Li}$ cells at $60^{\circ} \mathrm{C}$. The charge-discharge profiles of the solid-state cells using (e) PEO-LiTFSI and (f) ANF/PEO-FF electrolytes at $0.4 \mathrm{C}$ and $60^{\circ} \mathrm{C}$, respectively. (g) Cycling performance, (h) Coulombic efficiency and (i) average discharge voltage change of the solidstate $\mathrm{LiFePO}_{4} / \mathrm{Li}$ cells at $0.4 \mathrm{C}$ and $60^{\circ} \mathrm{C}$ for 100 cycles.

to the high polarization (or severe charge/discharge curve deformation) to the increase of the internal resistance of the battery and the low $\mathrm{Li}^{+}$ion diffusivity in the solidstate electrolyte and the electrolyte/electrode interface $[15,56,72,91-93]$. Note that all the solid-state cells exhibited much higher Coulombic efficiencies of nearly $100 \%$ during the whole cycling than the traditional LIBs with the organic liquid electrolytes (Fig. 6h). Besides, the ANF-containing cells showed less polarization than the ANF-free cell (Fig. 6e, $\mathrm{f}$ and Fig. S12b), and the ANF/ PEO-FF and ANF/PEO-DF CPE-based cells also had higher average discharge potential (around $3.3 \mathrm{~V}$ ) than the PEO-LiTFSI (around 3.2 V) electrolyte-based cell during the long-term cycling (Fig. 6i).

The impedance change of the all-solid-state $\mathrm{LiFePO}_{4} / \mathrm{Li}$ cells was further disclosed by EIS measurements at $30^{\circ} \mathrm{C}$ (Fig. S13). An equivalent circuit model was given in Fig. S13a, where $R_{\mathrm{e}}, R_{\mathrm{i}}$, and $R_{\mathrm{ct}}$ represent the ohmic re- sistance, interfacial resistance and charge transfer resistance, respectively [69]. The $R_{\mathrm{i}}$ values of the PEOLiTFSI, ANF/PEO-FF and ANF/PEO-DF electrolytebased cells before and after the charge/discharge cycling were 1570 and $965 \mathrm{ohm}, 1050$ and $473 \mathrm{ohm}$, and 1190 and $423 \mathrm{ohm}$, respectively, while the corresponding $R_{\mathrm{ct}}$ values before and after the cycling were 3820 and 36,035 ohm, 1810 and 14,627 ohm, and 2410 and 19,677 ohm, respectively. Overall, the ANF/PEO-FF (around 2860 and $15,100 \mathrm{ohm})$ and the ANF/PEO-DF (3600 and 20,100 ohm) CPE-based cells had lower total resistances than the PEO-LiTFSI electrolyte-based cell (5390 and $37,000 \mathrm{ohm}$ ) before and after the 100 cycles, respectively. This not only indicates the much rapid charge transfer in the CPE-based LIBs and again verifies the positive effect of the 3D ANF frameworks [69], but also explains the more and more severe charge/discharge curve deformation or polarization during the cycling process to some 
extent, though deeper investigation of the deformation behavior is needed in future work.

\section{CONCLUSIONS}

In summary, 3D porous ANF films were facilely prepared by the traditional blade coating method, and then flexible CPE membranes with 3D ANF frameworks were acquired by filling the PEO-LiTFSI electrolyte in the 3D ANF scaffolds. Because of the incorporation of the 3D ANF frames, the CPE membranes showed higher mechanical strength (up to $10.0 \mathrm{MPa}$ ) and thermostability (up to $420^{\circ} \mathrm{C}$ ) and wider electrochemical window $\left(4.6 \mathrm{~V}\right.$ at $\left.60^{\circ} \mathrm{C}\right)$ than the pristine PEO-LiTFSI electrolyte $\left(0.2 \mathrm{MPa}, 366^{\circ} \mathrm{C}\right.$ and $4.1 \mathrm{~V})$. The CPEs also exhibited higher ionic conductivities (e.g., two times that of the pristine electrolyte at ambient temperature), owing to the inhibition of the PEO crystallization, facilitation of the LiTFSI dissociation, and the continuous $\mathrm{Li}^{+}$ion transport at the $3 \mathrm{D}$ ANF framework/PEO-LiTFSI interfaces. Consequently, the CPE membranes had significantly enhanced interfacial resistance against $\mathrm{Li}$ dendrites $\left(1000 \mathrm{~h}\right.$ at $0.10 \mathrm{~mA} \mathrm{~cm}^{-2}$ and $30^{\circ} \mathrm{C}$ ), compared with the pristine electrolyte-based cell (short circuit in $13 \mathrm{~h}$ ). The CPE-based all-solid-state $\mathrm{LiFePO}_{4} / \mathrm{Li}$ cells exhibited better cycling performance (e.g., $130 \mathrm{~mA} \mathrm{~h} \mathrm{~g}^{-1}$ with $93 \%$ retention after 100 cycles at $0.4 \mathrm{C})$ than the ANF-free cell $\left(82 \mathrm{~mA} \mathrm{~h} \mathrm{~g}^{-1}\right.$ with $66 \%$ retention). This study provides a simple and effective method to fabricate high-performance CPEs with 3D nanofiller framework for potential Li metal battery applications.

Received 28 November 2019; accepted 26 December 2019; published online 20 January 2020

1 Zhang X, Cheng X, Zhang Q. Nanostructured energy materials for electrochemical energy conversion and storage: a review. J Energy Chem, 2016, 25: 967-984

2 Cao G. Solvent-salt synergy offers a safe pathway towards next generation high voltage Li-ion batteries. Sci China Mater, 2018, 61: 1360-1362

3 Yang X, Sun Q, Zhao C, et al. High-areal-capacity all-solid-state lithium batteries enabled by rational design of fast ion transport channels in vertically-aligned composite polymer electrodes. Nano Energy, 2019, 61: 567-575

4 Xin S, You Y, Wang S, et al. Solid-state lithium metal batteries promoted by nanotechnology: progress and prospects. ACS Energy Lett, 2017, 2: 1385-1394

5 Watanabe T, Inafune Y, Tanaka M, et al. Development of all-solidstate battery based on lithium ion conductive polymer nanofiber framework. J Power Sources, 2019, 423: 255-262

$6 \mathrm{Wu}$ H, Zhang Y, Deng Y, et al. A lightweight carbon nanofiberbased 3D structured matrix with high nitrogen-doping level for lithium metal anodes. Sci China Mater, 2019, 62: 87-94

7 Zhang H, Li C, Piszcz M, et al. Single lithium-ion conducting solid polymer electrolytes: advances and perspectives. Chem Soc Rev, 2017, 46: 797-815

$8 \mathrm{Yu} \mathrm{D,} \mathrm{Li} \mathrm{X,} \mathrm{Xu} \mathrm{J.} \mathrm{Safety} \mathrm{regulation} \mathrm{of} \mathrm{gel} \mathrm{electrolytes} \mathrm{in} \mathrm{electro-}$ chemical energy storage devices. Sci China Mater, 2019, 62: 15561573

9 Yang C, Fu K, Zhang Y, et al. Protected lithium-metal anodes in batteries: from liquid to solid. Adv Mater, 2017, 29: 1701169

10 Tan SJ, Zeng XX, Ma Q, et al. Recent advancements in polymerbased composite electrolytes for rechargeable lithium batteries. Electrochem Energ Rev, 2018, 1: 113-138

11 Tao C, Gao MH, Yin BH, et al. A promising TPU/PEO blend polymer electrolyte for all-solid-state lithium ion batteries. Electrochim Acta, 2017, 257: 31-39

12 Wan J, Xie J, Kong X, et al. Ultrathin, flexible, solid polymer composite electrolyte enabled with aligned nanoporous host for lithium batteries. Nat Nanotechnol, 2019, 14: 705-711

$13 \mathrm{He} \mathrm{K}$, Chen C, Fan R, et al. Polyethylene oxide/garnet-type $\mathrm{Li}_{6.4} \mathrm{La}_{3} \mathrm{Zr}_{1.4} \mathrm{Nb}_{0.6} \mathrm{O}_{12}$ composite electrolytes with improved electrochemical performance for solid state lithium rechargeable batteries. Compos Sci Tech, 2019, 175: 28-34

14 Liu L, Li M, Chu L, et al. Facile fabrication of flexible Si-based nanocomposite films as high-rate anodes by layer-by-layer selfassembly. Appl Surf Sci, 2019, 476: 501-512

15 Zhang Y, Lu W, Cong L, et al. Cross-linking network based on poly(ethylene oxide): solid polymer electrolyte for room temperature lithium battery. J Power Sources, 2019, 420: 63-72

16 Duan H, Fan M, Chen WP, et al. Extended electrochemical window of solid electrolytes via heterogeneous multilayered structure for high-voltage lithium metal batteries. Adv Mater, 2019, 31: 1807789

17 He ZJ, Fan LZ. Poly(ethylene carbonate)-based electrolytes with high concentration Li salt for all-solid-state lithium batteries. Rare Met, 2018, 37: 488-496

18 Hu J, Wang W, Zhou B, et al. Poly(ethylene oxide)-based composite polymer electrolytes embedding with ionic bond modified nanoparticles for all-solid-state lithium-ion battery. J Membrane Sci, 2019, 575: 200-208

19 Suriyakumar S, Gopi S, Kathiresan M, et al. Metal organic framework laden poly(ethylene oxide) based composite electrolytes for all-solid-state Li-S and Li-metal polymer batteries. Electrochim Acta, 2018, 285: 355-364

20 Zhao CZ, Zhang XQ, Cheng XB, et al. An anion-immobilized composite electrolyte for dendrite-free lithium metal anodes. Proc Natl Acad Sci USA, 2017, 114: 11069-11074

$21 \mathrm{Li} \mathrm{W}$, Sun C, Jin J, et al. Realization of the $\mathrm{Li}^{+}$domain diffusion effect via constructing molecular brushes on the LLZTO surface and its application in all-solid-state lithium batteries. J Mater Chem A, 2019, 7: 27304-27312

22 Fu X, Li C, Wang Y, et al. Building ion-conduction highways in polymeric electrolytes by manipulating protein configuration. ACS Appl Mater Interfaces, 2018, 10: 4726-4736

23 Chen L, Li Y, Li SP, et al. PEO/garnet composite electrolytes for solid-state lithium batteries: from "ceramic-in-polymer" to "polymer-in-ceramic”. Nano Energy, 2018, 46: 176-184

24 Chen S, Wang J, Zhang Z, et al. In-situ preparation of poly(ethylene oxide) $/ \mathrm{Li}_{3} \mathrm{PS}_{4}$ hybrid polymer electrolyte with good nanofiller distribution for rechargeable solid-state lithium batteries. J Power Sources, 2018, 387: 72-80

25 Zhu L, Zhu P, Fang Q, et al. A novel solid PEO/LLTO-nanowires polymer composite electrolyte for solid-state lithium-ion battery. 
Electrochim Acta, 2018, 292: 718-726

26 Lin D, Yuen PY, Liu Y, et al. A silica-aerogel-reinforced composite polymer electrolyte with high ionic conductivity and high modulus. Adv Mater, 2018, 30: 1802661

27 Tang W, Tang S, Zhang C, et al. Simultaneously enhancing the thermal stability, mechanical modulus, and electrochemical performance of solid polymer electrolytes by incorporating $2 \mathrm{D}$ sheets. Adv Energy Mater, 2018, 8: 1800866

28 Dirican M, Yan C, Zhu P, et al. Composite solid electrolytes for allsolid-state lithium batteries. Mater Sci Eng-R-Rep, 2019, 136: 2746

29 Gomari S, Esfandeh M, Ghasemi I. All-solid-state flexible nanocomposite polymer electrolytes based on poly(ethylene oxide): lithium perchlorate using functionalized graphene. Solid State Ion, 2017, 303: 37-46

30 Fu KK, Gong Y, Dai J, et al. Flexible, solid-state, ion-conducting membrane with 3D garnet nanofiber networks for lithium batteries. Proc Natl Acad Sci USA, 2016, 113: 7094-7099

31 Wang X, Zhai H, Qie B, et al. Rechargeable solid-state lithium metal batteries with vertically aligned ceramic nanoparticle/polymer composite electrolyte. Nano Energy, 2019, 60: 205-212

32 Zhai $\mathrm{H}, \mathrm{Xu}$ P, Ning M, et al. A flexible solid composite electrolyte with vertically aligned and connected ion-conducting nanoparticles for lithium batteries. Nano Lett, 2017, 17: 3182-3187

33 Gong Y, Fu K, Xu S, et al. Lithium-ion conductive ceramic textile: a new architecture for flexible solid-state lithium metal batteries. Mater Today, 2018, 21: 594-601

34 Xie H, Yang C, Fu KK, et al. Flexible, scalable, and highly conductive garnet-polymer solid electrolyte templated by bacterial cellulose. Adv Energy Mater, 2018, 8: 1703474

35 Bae J, Li Y, Zhang J, et al. A 3D nanostructured hydrogel-framework-derived high-performance composite polymer lithium-ion electrolyte. Angew Chem Int Ed, 2018, 57: 2096-2100

36 Bae J, Li Y, Zhao F, et al. Designing 3D nanostructured garnet frameworks for enhancing ionic conductivity and flexibility in composite polymer electrolytes for lithium batteries. Energy Storage Mater, 2018, 15: 46-52

37 Li D, Chen L, Wang T, et al. 3D fiber-network-reinforced bicontinuous composite solid electrolyte for dendrite-free lithium metal batteries. ACS Appl Mater Interfaces, 2018, 10: 7069-7078

38 Wang $\mathrm{X}$, Zhang $\mathrm{Y}$, Zhang $\mathrm{X}$, et al. Lithium-salt-rich $\mathrm{PEO} / \mathrm{Li}_{0.3} \mathrm{La}_{0.557} \mathrm{TiO}_{3}$ interpenetrating composite electrolyte with three-dimensional ceramic nano-backbone for all-solid-state lithium-ion batteries. ACS Appl Mater Interfaces, 2018, 10: 2479124798

39 Fu KK, Gong Y, Hitz GT, et al. Three-dimensional bilayer garnet solid electrolyte based high energy density lithium metal-sulfur batteries. Energy Environ Sci, 2017, 10: 1568-1575

40 Zhang M, Gui AL, Sun W, et al. High capacity utilization of Li metal anodes by application of celgard separator-reinforced ternary polymer electrolyte. J Electrochem Soc, 2019, 166: A2142A2150

41 Lyu J, Liu L, Zhao X, et al. Facile fabrication of multifunctional aramid nanofiber films by spin coating. J Mater Eng Perform, 2016, 25: 4757-4763

42 Lyu J, Wang X, Liu L, et al. High strength conductive composites with plasmonic nanoparticles aligned on aramid nanofibers. Adv Funct Mater, 2016, 26: 8435-8445

43 Yang M, Cao K, Yeom B, et al. Aramid nanofiber-reinforced transparent nanocomposites. J Composite Mater, 2015, 49: 1873-
1879

44 Wang F, Wu Y, Huang Y, et al. Strong, transparent and flexible aramid nanofiber/POSS hybrid organic/inorganic nanocomposite membranes. Compos Sci Tech, 2018, 156: 269-275

45 Kwon SR, Elinski MB, Batteas JD, et al. Robust and flexible aramid nanofiber/graphene layer-by-layer electrodes. ACS Appl Mater Interfaces, 2017, 9: 17125-17135

46 Lyu J, Liu Z, Wu X, et al. Nanofibrous kevlar aerogel films and their phase-change composites for highly efficient infrared stealth. ACS Nano, 2019, acsnano.8b08913

47 Tung SO, Ho S, Yang M, et al. A dendrite-suppressing composite ion conductor from aramid nanofibres. Nat Commun, 2015, 6 : 6152

48 Hu S, Lin S, Tu Y, et al. Novel aramid nanofiber-coated polypropylene separators for lithium ion batteries. J Mater Chem A, 2016, 4: 3513-3526

49 Zhang H, Zhang Y, Xu T, et al. Poly ( $m$-phenylene isophthalamide) separator for improving the heat resistance and power density of lithium-ion batteries. J Power Sources, 2016, 329: 8-16

50 Lyu J, Hammig MD, Liu L, et al. Stretchable conductors by kirigami patterning of aramid-silver nanocomposites with zero conductance gradient. Appl Phys Lett, 2017, 111: 161901

51 Lyu J, Zhao X, Hou X, et al. Electromagnetic interference shielding based on a high strength polyaniline-aramid nanocomposite. Compos Sci Tech, 2017, 149: 159-165

52 Li W, Zhang S, Wang B, et al. Nanoporous adsorption effect on alteration of the $\mathrm{Li}^{+}$diffusion pathway by a highly ordered porous electrolyte additive for high-rate all-solid-state lithium metal batteries. ACS Appl Mater Interfaces, 2018, 10: 23874-23882

53 Das S, Ghosh A. Charge carrier relaxation in different plasticized PEO/PVDF-HFP blend solid polymer electrolytes. J Phys Chem B, 2017, 121: 5422-5432

54 Lopez J, Sun Y, Mackanic DG, et al. A dual-crosslinking design for resilient lithium-ion conductors. Adv Mater, 2018, 30: 1804142

55 Sheng $\mathrm{O}$, Jin $\mathrm{C}$, Luo J, et al. $\mathrm{Mg}_{2} \mathrm{~B}_{2} \mathrm{O}_{5}$ nanowire enabled multifunctional solid-state electrolytes with high ionic conductivity, excellent mechanical properties, and flame-retardant performance. Nano Lett, 2018, 18: 3104-3112

56 Sun $\mathrm{Z}$, Li Y, Zhang S, et al. g- $\mathrm{C}_{3} \mathrm{~N}_{4}$ nanosheets enhanced solid polymer electrolytes with excellent electrochemical performance, mechanical properties, and thermal stability. J Mater Chem A, 2019, 7: 11069-11076

57 Khurana R, Schaefer JL, Archer LA, et al. Suppression of lithium dendrite growth using cross-linked polyethylene/poly(ethylene oxide) electrolytes: a new approach for practical lithium-metal polymer batteries. J Am Chem Soc, 2014, 136: 7395-7402

58 Stone GM, Mullin SA, Teran AA, et al. Resolution of the modulus versus adhesion dilemma in solid polymer electrolytes for rechargeable lithium metal batteries. J Electrochem Soc, 2012, 159: A222-A227

59 Zhou Q, Ma J, Dong S, et al. Intermolecular chemistry in solid polymer electrolytes for high-energy-density lithium batteries. Adv Mater, 2019, 31: 1902029

60 Zhang Q, Liu K, Ding F, et al. Recent advances in solid polymer electrolytes for lithium batteries. Nano Res, 2017, 10: 4139-4174

61 Kharlampieva E, Kozlovskaya V, Sukhishvili SA. Layer-by-layer hydrogen-bonded polymer films: from fundamentals to applications. Adv Mater, 2009, 21: 3053-3065

62 Stephan AM, Prem Kumar T, Angulakshmi N, et al. Influence of calix[2]-p-benzo[4]pyrrole on the electrochemical properties of 
poly(ethylene oxide)-based electrolytes for lithium batteries. J Appl Polym Sci, 2011, 120: 2215-2221

63 Blazejczyk A, Wieczorek W, Kovarsky R, et al. Novel solid polymer electrolytes with single lithium-ion transport. J Electrochem Soc, 2004, 151: A1762

64 Blazejczyk A, Szczupak M, Wieczorek W, et al. Anion-binding calixarene receptors: synthesis, microstructure, and effect on properties of polyether electrolytes. Chem Mater, 2005, 17: 15351547

65 Karthik K, Murugan R. Lithium garnet based free-standing solid polymer composite membrane for rechargeable lithium battery. J Solid State Electrochem, 2018, 22: 2989-2998

66 Zhang J, Zang X, Wen $\mathrm{H}$, et al. High-voltage and free-standing poly(propylene carbonate) $/ \mathrm{Li}_{6.75} \mathrm{La}_{3} \mathrm{Zr}_{1.75} \mathrm{Ta}_{0.25} \mathrm{O}_{12}$ composite solid electrolyte for wide temperature range and flexible solid lithium ion battery. J Mater Chem A, 2017, 5: 4940-4948

67 Sasikumar M, Raja M, Krishna RH, et al. Influence of hydrothermally synthesized cubic-structured $\mathrm{BaTiO}_{3}$ ceramic fillers on ionic conductivity, mechanical integrity, and thermal behavior of $\mathrm{P}$ (VDF-HFP)/PVAc-based composite solid polymer electrolytes for lithium-ion batteries. J Phys Chem C, 2018, 122: 25741-25752

68 Pandian AS, Chen XC, Chen J, et al. Facile and scalable fabrication of polymer-ceramic composite electrolyte with high ceramic loadings. J Power Sources, 2018, 390: 153-164

69 Liu L, Chu L, Jiang $\mathrm{B}$, et al. $\mathrm{Li}_{1.4} \mathrm{Al}_{0.4} \mathrm{Ti}_{1.6}\left(\mathrm{PO}_{4}\right)_{3}$ nanoparticle-reinforced solid polymer electrolytes for all-solid-state lithium batteries. Solid State Ion, 2019, 331: 89-95

70 Wang Z, Huang X, Chen L. Understanding of effects of nano$\mathrm{Al}_{2} \mathrm{O}_{3}$ particles on ionic conductivity of composite polymer electrolytes. Electrochem Solid-State Lett, 2003, 6: E40

71 Liu W, Liu N, Sun J, et al. Ionic conductivity enhancement of polymer electrolytes with ceramic nanowire fillers. Nano Lett, 2015, 15: 2740-2745

72 Cheng SHS, He KQ, Liu Y, et al. Electrochemical performance of all-solid-state lithium batteries using inorganic lithium garnets particulate reinforced $\mathrm{PEO} / \mathrm{LiClO}_{4}$ electrolyte. Electrochim Acta, 2017, 253: 430-438

73 Liu L, Lyu J, Mo J, et al. Comprehensively-upgraded polymer electrolytes by multifunctional aramid nanofibers for stable allsolid-state Li-ion batteries. Nano Energy, 2020, 69: 104398

74 Wang Q, Song WL, Fan LZ, et al. Flexible, high-voltage and freestanding composite polymer electrolyte membrane based on triethylene glycol diacetate-2-propenoic acid butyl ester copolymer for lithium-ion batteries. J Membrane Sci, 2015, 492: 490-496

75 Zheng J, Hu YY. New insights into the compositional dependence of Li-ion transport in polymer-ceramic composite electrolytes. ACS Appl Mater Interfaces, 2018, 10: 4113-4120

76 Liu L, Wu X, Li T. Novel polymer electrolytes based on cationic polyurethane with different alkyl chain length. J Power Sources, 2014, 249: 397-404

77 Porcarelli L, Manojkumar K, Sardon H, et al. Single ion conducting polymer electrolytes based on versatile polyurethanes. Electrochim Acta, 2017, 241: 526-534

78 Mustapa SR, Aung MM, Ahmad A, et al. Preparation and characterization of Jatropha oil-based polyurethane as non-aqueous solid polymer electrolyte for electrochemical devices. Electrochim Acta, 2016, 222: 293-302

79 Lin D, Liu W, Liu Y, et al. High ionic conductivity of composite solid polymer electrolyte via in situ synthesis of monodispersed $\mathrm{SiO}_{2}$ nanospheres in poly(ethylene oxide). Nano Lett, 2016, 16:
459-465

80 Ke X, Cheng Y, Liu J, et al. Hierarchically bicontinuous porous copper as advanced 3D skeleton for stable lithium storage. ACS Appl Mater Interfaces, 2018, 10: 13552-13561

81 Yang T, Zheng J, Cheng Q, et al. Composite polymer electrolytes with $\mathrm{Li}_{7} \mathrm{La}_{3} \mathrm{Zr}_{2} \mathrm{O}_{12}$ garnet-type nanowires as ceramic fillers: mechanism of conductivity enhancement and role of doping and morphology. ACS Appl Mater Interfaces, 2017, 9: 21773-21780

82 Fan X, Ji X, Han F, et al. Fluorinated solid electrolyte interphase enables highly reversible solid-state Li metal battery. Sci Adv, 2018, 4: eaau9245

83 Chen L, Fan L. Dendrite-free Li metal deposition in all-solid-state lithium sulfur batteries with polymer-in-salt polysiloxane electrolyte. Energy Storage Mater, 2018, 15: 37-45

84 Zhu P, Yan C, Dirican M, et al. $\mathrm{Li}_{0.33} \mathrm{La}_{0.557} \mathrm{TiO}_{3}$ ceramic nanofiberenhanced polyethylene oxide-based composite polymer electrolytes for all-solid-state lithium batteries. J Mater Chem A, 2018, 6: 42794285

85 Liu S, Wang H, Imanishi N, et al. Effect of co-doping nano-silica filler and $\mathrm{N}$-methyl- $\mathrm{N}$-propylpiperidinium bis(trifluoromethanesulfonyl)imide into polymer electrolyte on Li dendrite formation in $\mathrm{Li} /$ poly(ethylene oxide)- $\mathrm{Li}\left(\mathrm{CF}_{3} \mathrm{SO}_{2}\right)_{2} \mathrm{~N} / \mathrm{Li}$. J Power Sources, 2011, 196: 7681-7686

86 Brissot C, Rosso M, Chazalviel JN, et al. Dendritic growth mechanisms in lithium/polymer cells. J Power Sources, 1999, 81-82: 925-929

87 Rosso M, Brissot C, Teyssot A, et al. Dendrite short-circuit and fuse effect on Li/polymer/Li cells. Electrochim Acta, 2006, 51: $5334-5340$

88 Xu Y, Zhou Y, Li T, et al. Multifunctional covalent organic frameworks for high capacity and dendrite-free lithium metal batteries. Energy Storage Mater, 2019

89 Chazalviel JN. Electrochemical aspects of the generation of ramified metallic electrodeposits. Phys Rev A, 1990, 42: 7355-7367

90 Zhang B, Zhang Y, Zhang N, et al. Synthesis and interface stability of polystyrene-poly(ethylene glycol)-polystyrene triblock copolymer as solid-state electrolyte for lithium-metal batteries. J Power Sources, 2019, 428: 93-104

91 Wu JF, Guo X. Nanostructured metal-organic framework (MOF)derived solid electrolytes realizing fast lithium ion transportation kinetics in solid-state batteries. Small, 2019, 15: 1804413

92 Shen B, Zhang TW, Yin YC, et al. Chemically exfoliated boron nitride nanosheets form robust interfacial layers for stable solidstate Li metal batteries. Chem Commun, 2019, 55: 7703-7706

93 Jung YC, Lee SM, Choi JH, et al. All solid-state lithium batteries assembled with hybrid solid electrolytes. J Electrochem Soc, 2015, 162: A704-A710

Acknowledgements This work was supported partially by Beijing Natural Science Foundation (L172036), Joint Funds of the Equipment Pre-Research and Ministry of Education (6141A020225), Par-Eu Scholars Program, Science and Technology Beijing 100 Leading Talent Training Project, Beijing Municipal Science and Technology Project (Z161100002616039), China Postdoctoral Science Foundation (2018M631419), and the Fundamental Research Funds for the Central Universities (2017ZZD02 and 2019QN001).

Author contributions $\mathrm{Li} \mathrm{M}$ conceived the project and designed the experiments. Liu L, Lyu J, Mo J, Peng P and Li J conducted the material synthesis and measurements. Liu L, Jiang B and Chu L wrote the paper. 
All authors discussed the results and commented on the manuscript.

Conflict of interest The authors declare no conflict of interest.

Supplementary information online version of the paper.

Supporting data are available in the

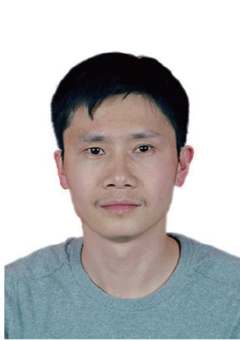

Lehao Liu is a postdoctoral researcher in the North China Electric Power University. He received a PhD degree in 2016 from the Northwestern Polytechnical University. During 20122015, he was a joint-training PhD student at the University of Michigan. After obtaining his $\mathrm{PhD}$ degree, he began to work as a chief engineer in CITIC Guoan MGL Power Source Technology Company. His research focuses on nano/micromaterials for energy storage.

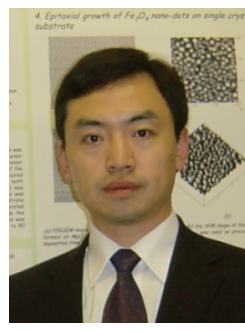

Meicheng $\mathbf{L i}$ is the Director of the Center for New Energy Materials and Photoelectric Technology at the School of Renewable Energy in North China Electric Power University. His current focus is lithium/sodium ion battery, including fundamental understanding, applied research and development, and flexible device design. He also has interest in R\&D of perovskite solar cells, battery system and other new energy materials and devices.

\section{基于三维芳纶纳米纤维骨架的柔性高压复合电解} 质膜及其固态锂金属电池

刘乐浩 ${ }^{1}$, 吕婧 ${ }^{2}$, 莫金珊 ${ }^{1}$, 彭鹏 ${ }^{1}$, 李静如 ${ }^{1}$, 姜冰 ${ }^{1}$, 褚立华 ${ }^{1}$, 李美成 ${ }^{1 *}$

摘要 聚合物电解质在锂金属电池中的应用受限于锂枝晶生长、 电化学不稳定性及较低的离子电导率. 为解决这些问题, 本文通过 向三维多孔芳纶纳米纤维(ANF)中填充聚环氧乙烷(PEO)-双三氟 甲基磺酰亚胺锂(LiTFSI)电解质, 制备了基于三维芳纶纳米纤维网 络骨架的柔性ANF/PEO-LiTFSI复合电解质薄膜. 由于其独特的构 造及离子在三维ANF/PEO-LiTFSI界面中的连续输运, 该复合电解 质膜具有比PEO-LiTFSI电解质膜更高的力学强度 $(10.0 \mathrm{MPa})$ 、热 稳定性、电化学稳定性 $\left(60^{\circ} \mathrm{C}\right.$ 下达 $\left.4.6 \mathrm{~V}\right)$ 和离子电导率, 以及较强的 抑制锂枝晶能力. 基于该复合电解质的固态 $\mathrm{LiFePO}_{4} / \mathrm{Li}$ 电池表现出 优异的循环性能(在0.4 C下充放电百次后的容量达 $130 \mathrm{~mA} \mathrm{~h} \mathrm{~g}^{-1}$ 、 保持率为 $93 \%)$. 该研究提供了一种基于三维骨架设计和制备高性 能电解质的有效方法, 有望应用于固态锂金属电池. 